\title{
The influence of the drainage regime on the installation and the response to vertical cyclic loading of suction caissons in dense sand
}

\author{
M. Stapelfeldt ${ }^{\mathrm{a}, *}$, B. Bienen ${ }^{\mathrm{b}}$, J. Grabe ${ }^{\mathrm{a}}$ \\ ${ }^{a}$ Institute of Geotechnical Engineering and Construction Management, Hamburg \\ University of Technology, Harburg, Hamburg, Germany \\ ${ }^{b}$ Centre for Offshore Foundation Systems, The University of Western Australia, \\ Crawley, Perth, WA, Australia
}

\begin{abstract}
Offshore wind turbines are considered as an integral part of renewable energy. Dense sand often characterises the sea bed and suction caisson foundations are increasingly used to support offshore wind turbines at North Sea sites. Significant experience with this technology exists in the oil and gas industry, although these platforms are typically located in deeper water with clay soils. Therefore, research is required to transfer the existing knowledge. This paper discusses a series of centrifuge tests that investigate the installation and the load bearing behaviour of suction caissons embedded in dense sand subjected to vertical cyclic loading. The effect of potential loosening of the internal soil plug during suction installation on the in-service foundation performance is evaluated through cone penetration tests inside the caisson following suction installation at different pumping flow rates. In accompanying tests, the load displacement behaviour in response to vertical cyclic loading is investigated, including significant excursions into tension. The results identify the pore fluid behaviour as the key factor affecting the response, with the pumping flow rate applied during installation being less influential. Based on the findings from the experiments a simplified approach for the prediction of suction caisson behaviour under vertical cyclic loading is presented.
\end{abstract}

Keywords: centrifuge, suction, foundation, sand

\footnotetext{
${ }^{*}$ Corresponding author

Email address: marc.stapelfeldt@tuhh.de (M. Stapelfeldt)
} 


\section{Introduction}

Decades before offshore wind energy started to emerge, suction caisson foundations, also called suction buckets, have been widely utilised for oil and gas developments in relatively deep waters with predominantly clay soils

5 (e. g. Eide and Andersen (1984); Bye et al. (1995) and Andersen et al. (2005)). Suction caissons, skirted large diameter structures, are increasingly considered for bottom fixed offshore wind turbines (OWT). Since sea beds in the North Sea often consist of dense sand, shallow suction caisson foundations typically feature aspect ratios between $L / D \approx 0.5$ and $L / D \approx 1$, where $L$ is the skirt length and $D$ the diameter.

Significant differences exist in suction caissons supporting OTWs compared to those serving as foundations for oil and gas platforms. OWTs are significantly lighter than most oil and gas platforms. In addition, the centre of gravity is located at a high altitude, which is challenging - especially for loads on the windward caissons of multipod jacket structures are small and might extend into tension, depending on the spacing between the caissons (Bienen et al., 2018b).

Experience with suction caisson foundations for OWTs is limited to date. crikshavn (Ibsen, 2008) and at offshore sites in the Horns Rev 2 and Dogere Bank wind warm (Tjelta, 2015). In addition, a suction bucket jacket was installed during the Borkum Riffgrund development in 2014 (Tjelta, 2015). Furthermore, Kelly et al. (2006a) and Houlsby et al. (2006) installed a single medium scale caissons near shore at Bothkennar and Luce Bay that were tested with a loading rig. In addition several small scale lab tests - mainly using a pressure chamber - were performed and published by Byrne and Houlsby (2002), Byrne and Houlsby (2004), Houlsby and Byrne (2005), and Kelly et al. (2006b). Furthermore, centrifuge test were performed and discussed by Allersma et al. (2000), Cox et al. (2014), and Kim et al. (2016) among others. As this database includes mainly loading tests for monopod structures and the data from prototype tests remains confidential, the available experience for multipod caisson based OWTs is limited.

Despite a growing number of successful prototype installations in sandy seabeds uncertainties regarding possible effects of the suction installation on 
the in-service load bearing behaviour still exist. Therefore, further insights into the installation mechanism in sand are required. The suction caisson installation in sand starts with the caisson penetrating into the soil due to its self-weight and with a venting valve, before the suction installation commences. Therefore suction pressure is generated inside the caisson while the valve is closed. As presented in Figure 1, seepage flow results from the differential pressure. The additional down force and the flow induced reduction of the tip resistance $\sigma_{\text {tip }}$ enable further caisson penetration - even in dense or very dense sand (Tjelta, 1995; Houlsby et al., 2005).

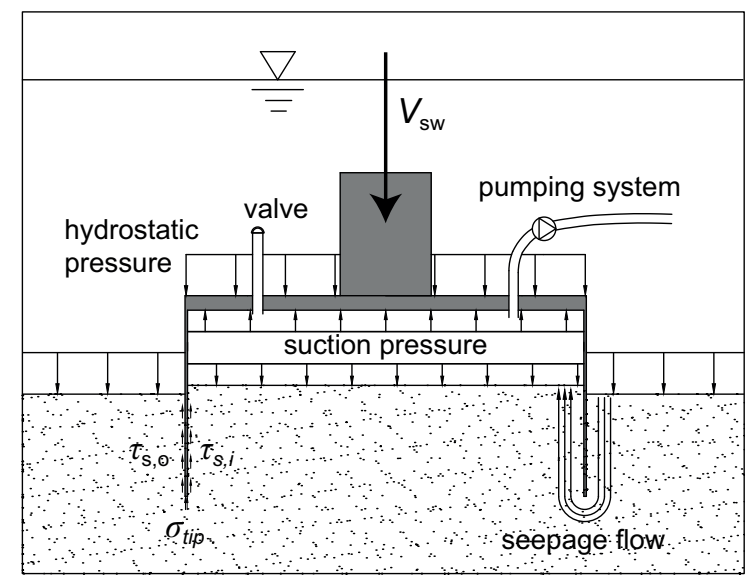

Figure 1: Suction installation in sand.

The suction installation can be predicted by different approaches published by Houlsby and Byrne (2005), Andersen et al. (2008) or Senders and Randolph (2009). However, there are no conclusive results on the effects of the installation on the plug state during and after the installation in those studies. Thus, Tran et al. (2004) and Tran and Randolph (2008) investigated the suction installation through centrifuge tests. Based on these experiments it was shown that the suction pressure indeed reduces the tip resistance. In addition it was found that rapid installation induced less plug heave in comparison to slow installation (Tran et al., 2004). Tran and Randolph (2008) found that the differential pressure always reaches a critical stage where the suction pressure increases steadily with the penetration depth. However, it was concluded that further tests are required to determine more reliable conclusions on the soil state of the plug during and after suction installation.

Bienen et al. (2018a,b) conducted a series of centrifuge tests on caissons 
installed in Baskarp sand. This study targeted the suction installation and the load bearing behaviour at different drainage conditions. The suction caisson installation was found to be feasible at a certain minimum pumping flow rate without significant plug loosening. Furthermore, no conclusive evidence of a possible influence of the suction installation on the load bearing behaviour was found. Instead, the drainage regime was identified to be crucial for the load bearing behaviour. Though, the soil plug was not investigated directly.

Another series of centrifuge experiments including particle image velocimetry (PIV) allowed a direct investigation on the soil plug state and therefore provided further insights into the mechanisms of self-weight and suction installation. The results of the image analysis of indicate that suction installation can lead to considerable soil plug loosening (Ragni et al., 2018, 2019). A loosened soil plug obviously is expected to yield an alternate response to loading, consequently the results of both investigations remain an issue for discussion.

75 Since the load deformation behaviour and a possible effect of the suction installation - especially when it comes to low magnitude compressive or tensile vertical loading - is crucial to the serviceability limit state of an OWT, further investigations are necessary to increase confidence in the caisson foundation technology. Therefore a novel series of centrifuge tests was planned. The experiments presented in this study aim to build on the latest test results published by Bienen et al. (2018b), Bienen et al. (2018a) and Ragni et al. $(2018,2019)$. Hence, the following questions are targeted:

- Depending on the pumping flow rate, considerable seepage is present in the soil plug during suction installation. Do consequences arise for the achievable penetration depth or in-service foundation performance from the suction installation?

- OWT foundations can become subject to low magnitude compressive and even tensile loads. What level of tensile loads can safely be carried without considerable heave, i. e. without compromising serviceability criteria?

- Since in-service performance is crucial for the design of an OWT, a simple prediction method for soil-structure interaction is particularly valuable. How can the response to cyclic loading be predicted? 


\section{Experimental arrangement and testing procedure}

95 questions. One series featured the suction installation with a subsequent cone penetration test (CPT) inside the suction caisson. The other series includes cyclic loading tests following the suction installation. The experiments were performed at $100 \mathrm{~g}$ in the Acutronic Model 661 centrifuge (Randolph et al., 1991; Randolph and Gaudin, 2017) at the University of Western Australia (UWA). These tests had the following requirements to ensure a realistic stress state during the model scale experiments:

- Caisson penetration at stress levels representative for prototype scale was required. Thus, the caisson had to be suspended just above the sand surface until the centrifuge had reached the target acceleration.

- The installation was to be done in a controlled manner to ensure reproducible conditions for each subsequent testing procedure - i. e. CPTs or cyclic loading tests.

- The CPTs and the cyclic loading were to be performed without stoppage of the centrifuge to retain the soil stress state resulting from the suction installation.

- CPTs at free field sites were to be performed before and after the caisson tests to characterise the soil samples itself, to confirm uniformity of each sample used in this study and to facilitate between CPT profiles obtained within the suction caisson and at the free field sites, respectively.

\subsection{Centrifuge test arrangements}

While similar conditions for the suction installation were targeted, different test arrangements were employed for the two complementary series of centrifuge tests discussed here. Both test series featured a minimum sample

height of $200 \mathrm{~mm}$. The water table had to be at least $100 \mathrm{~mm}$ above the sand surface to ensure that the model caisson including the three way valve, are submerged to minimise changes in buoyancy during installation. 


\subsubsection{Test set-up for CPTs inside the caisson}

The performance of a CPT inside the caisson - a testing method inspired by the work of Tran (2005) - required several improvements before the suction caisson installation and the CPT in one flight became feasible. Two caissons with similar diameters and aspect ratios of $D / L=0.5$ and $D / L=1$ were manufactured and equipped with the same set of sensors. In this set-up the CPT was clamped to the actuator and the caisson was connected to the actuator with a steel wire. The purpose of this set-up presented in Figure 2 was suspension of the foundation prior to testing. In addition, this arrangement allowed self-weight penetration to take place at a controlled rate. It also enabled the performance of the CPT without stopping the centrifuge, which is a major improvement compared to the set-up presented by Tran (2005).

In this arrangement, the model caisson and the CPT were lowered without relative displacement. The vertical movement was controlled via a feedback loop, maintaining a constant distance measured by the linear displacement transducer (LDT) shown in Figure 2. A guide rod arrangement ensured verticality during the installation. The rod connected to the caisson also contributed to the targeted self-weight of $350 \mathrm{~N}$ in model scale, i. e. $3.5 \mathrm{MN}$ in prototype scale.

The miniature cone shown in Figure 2 had a diameter of $D_{c p t}=6.3 \mathrm{~mm}$ and was manufactured specifically for these tests. The cone tip was placed inside the caisson lid during the suction caisson installation. The opening was sealed with two o-rings. As described in detail in Stapelfeldt et al. (2018), the utilisation of this small diameter cone ensured the insertion of a minimum volume object while maximising its rigidity as well as its clearance from the skirt. Thus, a minimum distance between the cone and the skirt of at least three times the cone diameter was maintained.

\subsubsection{Test set-up for cyclic loading tests}

In this series of cyclic loading tests the model caisson was carried by an actuator, which was mounted on top of the strongbox. A rod and the load cell attached the model caisson to the actuator. The LDT was placed on top of the model caisson on one end and was clamped to the horizontal support beams of the actuator on the other end. A camera was mounted on top of the vertical actuator carriage with the purpose of showing the status of the three way valve. The three way valve on the caisson lid was able to vent to ambient, to connect the caisson to the syringe pump and to be sealed (see 
Figure 3). The three way valve was operated by an electric winch positioned next to the actuator support beams by means of a pulley system. The syringe pump (House, 2002) was mounted on the back of the strong box as shown in Figure 4 .

The performance of the pulley system was controlled by an additional camera located on the edge of the strong box. This camera also provided a side view of the installation. The light panel next to the camera was required to ensure sufficient illumination of the experimental apparatus.

\subsubsection{Caisson model and test instrumentation}

170 $40 \mathrm{~mm}$, which when tested at $100 \mathrm{~g}$ represents a diameter $D=8 \mathrm{~m}$ and a skirt length of $L=4 \mathrm{~m}$ in prototype scale. This model caisson, previously used by Bienen et al. (2018b,a), was manufactured from a solid block of aluminium. The wall thickness of the skirt was $t=0.5 \mathrm{~mm}$, which corresponds to a aspect ration $L / D=0.5$ a second caisson with the same diameter but an aspect ration $L / D=1$ was also used. The skirt of this $L=80 \mathrm{~mm}$ long caisson also had a model wall thickness of $t=0.5 \mathrm{~mm}$. This yields a ration of $D / t=160$ for each model caisson.

180 Each caisson was equipped with a pore pressure transducer (PPT) and two total pressure transducers (TTP) - one at the lid invert and another one at the top of the lid. The caisson model was connected to a load cell with a maximum capacity of $8 \mathrm{kN}$ by means of a rigid rod for the cyclic loading tests. The self-weight and the loading of the model caisson were applied with the

\subsubsection{Soil sample and pore fluid preparation}

The fine silica sand was pluviated from a height of approximately $1.2 \mathrm{~m}$ by means of an automatic pluviator. After reaching a total sample height of at least $200 \mathrm{~mm}$, the surface was vacuum levelled. The unit weight was 190 determined from weight and volume measurements. The relative densities $D_{r}$ for the three samples used in this study were $0.84 \pm 0.03$. The peak friction angle of fine silica sand was $\varphi_{p}=43^{\circ}$ at $\sigma=20 \mathrm{kPa}$ (Lehane and Liu, 2013). The particle size distribution of fine silica sand presented in Figure 5. The minimum void ratio is $e_{\min }=0.46$ and the maximum void ratio is is similar to fine silica sand, is presented. However, Baskarp sand has more 
angular grains and shows enhanced dilation compared to fine silica sand (Bienen et al., 2018a).

Each sand sample was saturated from the base after the pluviation. In order to satisfy the scaling laws for dynamic motion and diffusion (Taylor, 2011), the viscosity $\eta$ of the pore fluid was increased from approximately $\eta_{w}=1 \mathrm{cSt}$ for water to $\eta=100 \mathrm{cSt}$ by means of the addition of methyl cellulose ether (DOW, 2002). Hereby an effective permeability of the soil sample - i. e. $\quad k_{f}=1 \cdot 10^{-4} \mathrm{~m} / \mathrm{s}$ - at $100 \mathrm{~g}$ was targeted. The effective permeability of the saturated soil can be adjusted trough the amount of methyl cellulose ether powder diluted in water. Through the addition of more methyl cellulose ether powder, the viscosity of the pore fluid was increased to $\eta=300 \mathrm{cSt}$ in sample no. 2. Thus, a prototype effective permeability of $k_{f}=3.3 \cdot 10^{-5} \mathrm{~m} / \mathrm{s}$ was achieved. This allowed investigation of the effect of 210 uncertainty in the in situ effective permeability. The effective permeability coefficients are representative of typical North Sea sands (Tan and Scott, 1987).

\subsubsection{Sample characterisation: CPTs at free field sites}

Before and after the suction caisson models were tested, CPTs were performed at $100 \mathrm{~g}$. A centrifuge scale penetrometer with a model diameter of $D_{c p t}=10 \mathrm{~mm}$ and the smaller one with a diameter of $D_{c p t}=6.3 \mathrm{~mm}$ were penetrated into the soil at a constant velocity of $v_{c p t}=1 \mathrm{~mm} / \mathrm{s}$, which is expected to result in drained conditions (Finnie and Randolph, 1994). The CPTs were performed to confirm the soil characteristics and the uniformity within and between each sample.

Figure 6 shows all CPT profiles of cone tip resistance $q_{c}$ with penetration depth $z$ normalised by the caisson skirt length $L=40 \mathrm{~mm}$. The presented profiles confirm the uniformity within and between each soil sample. CPTs with both penetrometers $-D_{c p t}=10 \mathrm{~mm}$ (solid lines) and $D_{c p t}=6.3 \mathrm{~mm}$ (dashed lines) - were conducted in sample no. 2 and no. 3. It is noted that CPT profiles from both penetrometers are similar. This ensures comparability between the cone tip resistance profiles obtained at the free field sites and those obtained from the $D_{c p t}=6.3 \mathrm{~mm}$ CPTs through the caisson lid.

\subsection{Testing nomenclature}

${ }_{230}$ Table 1 summarises all 15 suction caisson tests. The tests are named as follows: 
- The letters INST characterise tests where a CPT was conducted through the lid following suction caisson installation. The letters CYC indicate that a cyclic loading test followed the suction installation.

- The numbers $1,2,3,4,5$ group tests that feature similar pumping flow rates during the suction caisson installation.

- The letter $\mathrm{H}$ represents tests in sand with a higher effective permeability, while L indicates a test in sand with a lower effective permeability.

- The last letter(s) indicate(s) different pumping flow rates: $\mathrm{S}=$ slow, $\mathrm{MS}=$ medium slow, $\mathrm{M}=$ moderate, $\mathrm{F}=$ fast, $\mathrm{SF}=$ super fast.

\subsection{Testing procedure}

Table 1: Centrifuge testing programme

\begin{tabular}{|c|c|c|c|c|}
\hline \multicolumn{2}{|c|}{ Test name } & \multirow{2}{*}{$\begin{array}{c}\text { Permeability } \\
k_{f}(\mathrm{~m} / \mathrm{s})\end{array}$} & \multirow{2}{*}{$\begin{array}{c}\text { Pumping flow rate } \\
q\left(\mathrm{~mm}^{3} / \mathrm{s}\right)\end{array}$} & \multirow{2}{*}{$\begin{array}{c}\text { Model skirt length } \\
L(\mathrm{~mm})\end{array}$} \\
\hline 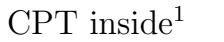 & Cyclic loading 1 & & & \\
\hline INST-1-H-S & CYC-1-H-S & $1.0 \cdot 10^{-4}$ & $266.2(512.4)^{2}$ & 40 \\
\hline INST-1-H-MS & CYC-1-H-MS & $1.0 \cdot 10^{-4}$ & 332.8 & 80 \\
\hline INST-2-H-M & CYC-2-H-M & $1.0 \cdot 10^{-4}$ & 665.6 & 40 \\
\hline INST-3-H-F & CYC-3-H-F & $1.0 \cdot 10^{-4}$ & 1664.0 & 40 \\
\hline INST-3-H-SF & - & $1.0 \cdot 10^{-4}$ & 2662.4 & 80 \\
\hline INST-4-L-M & CYC-4-L-M & $3.3 \cdot 10^{-5}$ & 665.6 & 40 \\
\hline INST-5-L-F & CYC-5-L-F & $3.3 \cdot 10^{-5}$ & 1664.0 & 40 \\
\hline INST-5-L-SF & - & $3.3 \cdot 10^{-5}$ & 2662.4 & 40 \\
\hline INST-5-L-SF2 & - & $3.3 \cdot 10^{-5}$ & 2662.4 & 80 \\
\hline
\end{tabular}

Each test summarised in Table 1 was performed in a different location. A total of six cyclic loading tests that featured the same installation process as the corresponding tests with a CPT through the caisson lid were performed. It is noted that all four installations conducted with suction caisson that had a model skirt length of $L=80 \mathrm{~mm}$ were not completed due to premature refusal. Thus, test CYC-1-H-MS was terminated once the refusal occurred. The respective CPTs were performed inside the incompletely installed caissons. 


\subsubsection{Caisson installation}

The suction caisson installation for both parallel series of tests was performed as follows:

(1) The self-weight penetration was performed under load control at a constant loading rate of $1 \mathrm{~N} / \mathrm{s}$ in model scale. A total vertical load of $V=350 \mathrm{~N}$ was applied on the model caisson, which equals $V=3.5 \mathrm{MN}$ or $V / A=70 \mathrm{kPa}$ in prototype scale. The initial load on the actuator during the installations for CPTs through the lid was equal to the submerged dead-weight. This load was reduced to zero at a constant rate of $1 \mathrm{~N} / \mathrm{s}$ during the self-weight penetration. At this point the steel wire went slack and the self-weight penetration terminated. The three way valve vented to ambient until the self-weight penetration completed.

(2) Once the self-weight penetration stopped, the valve was switched to achieve a hydraulic connection between the caisson internal and the syringe pump without stopping the centrifuge. A constant pumping flow rate was applied, which was maintained until the caisson penetration stopped.

(3) The in-flight suction caisson installation was completed by sealing the valve without stopping the centrifuge.

\subsubsection{CPT through the caisson lid}

The CPTs inside the caissons were performed subsequently to suction caisson installation as follows:

(1) A waiting period of at least $60 \mathrm{~s}$ at $100 \mathrm{~g}$ was maintained before the CPT commenced to ensure that the suction pressure inside the caisson had dissipated.

(2) Subsequently and without stopping the centrifuge, the CPT was performed through the caisson lid at a constant penetration velocity of $v_{c p t}=1 \mathrm{~mm} / \mathrm{s}$, which is expected to result in drained conditions (Finnie and Randolph, 1994). The cone was penetrated in to a depth of at least $z / L=1.2$. The maximum penetration depth was limited by the clearance between the guide rod and the bottom plate of the lower actuator clamp. 
Table 2: Cyclic loading sequences

\begin{tabular}{lcccc}
\hline Sequence number & 1 & 2 & 3 & 4 \\
\hline Number of cycles $n$ & 1000 & 100 & 10 & 1 \\
Cyclic load amplitude $V(\mathrm{~N})$ & $40 \pm 80$ & $40 \pm 200$ & $40 \pm 400$ & $40 \pm 600$ \\
Cyclic stress amplitude $V / A(\mathrm{kPa})$ & $8 \pm 16$ & $8 \pm 40$ & $8 \pm 80$ & $8 \pm 120$ \\
\hline
\end{tabular}

(3) Once the maximum penetration depth was reached, the cone penetrometer was extracted from the soil until the tip retracted inside the caisson lid again. The tests were terminated before the caisson was disturbed by subjecting the steel wire to tension.

\subsubsection{Cyclic loading of the caisson}

Following the suction caisson installation with different pumping flow rates in each test, the same cyclic loading history was applied to investigate the effect on the load-displacement behaviour. This cyclic loading history shown in Figure 7 subjects the caisson to tensile as well as compressive load in each cycle.This load history was evaluated using an integrated in-house code featuring aero- and hydrodynamic, structural and macro-element foundation models (Bienen and Cassidy, 2006; Senders, 2008). The same cyclic loading history, which was selected to represent the windward caisson of a $8 \mathrm{MW}$ OWT with a jacket substructure in a water depth of $40 \mathrm{~m}$ under operational conditions, was also utilised in centrifuge tests performed on suction buckets in Baskarp sand at similar and lower effective permeabilities (Bienen et al., 2018b). Neither the dimensions nor the loading conditions reflect any particular site. The cyclic loading test were performed as follows:

(1) A waiting period of at least $60 \mathrm{~s}$ at $100 \mathrm{~g}$ was maintained before the loading test to ensure that the suction pressure inside the caisson dissipated.

(2) The self-weight was increased to $V=585 \mathrm{~N}$ in model scale $(V / A=$ $116 \mathrm{kPa}$ ). This represented the full self-weight of the jacket and the superstructure of the OWT - including tower, nacelle and rotor - applied to the tested caisson. This vertical load was maintained until the excess pore pressured at the lid invert dissipated and no further settlements were observed. 
(3) The vertical load was reduced to $V_{a v}=40 \mathrm{~N}$ in model scale $\left((V / A)_{a v}=\right.$ $8 \mathrm{kPa})$. This represents the average vertical load at the windward caisson of a suction caisson jacket.

(4) The average vertical load of $V=40 \mathrm{~N}(V / A=8 \mathrm{kPa})$ was maintained throughout the entire cyclic loading test. The cyclic loading test was performed under load control. The cyclic loads were applied in packages of four sequences with four different, increasing load amplitudes. The respective load amplitudes and the number of cycles per sequence are shown in Table 2. At least six load packages were applied in each test as presented in Figure 7. This yields a minimum of $n=6666$ load cycles in each test.

The cyclic loads were applied at a loading frequency of $f=0.5 \mathrm{~Hz}$ and with regular sinusoidal amplitude. Loading due to wind, waves and current in a natural environment is expected to be highly irregular. However, the regular loading scheme was conceived to represent realistic drainage conditions in a reproducible manner. In addition this approach facilitates the evaluation of each load sequence (LSQ) and comparison between tests.

\section{Results and discussion}

The experimental results are presented in non-dimen-sional form, unless stated otherwise. Positive values indicate compression and downward displacements, whereas negative values represent tension and upward displacements.

\subsection{Suction caisson installation}

Figure 8 shows the achieved self-weight and suction-assisted total penetration depths. The majority of installations were terminated at more than $z / L=0.85$ skirt penetration. The soil displaced by the skirt volume increases the plug volume by approximately $2 \%$ - assuming that $50 \%$ of the sand moves inwards during the self-weight penetration and $100 \%$ moving into the caisson during the suction diction installation. Consequently, a skirt penetration of $z / L \approx 0.98$ indicates full installation without plug heave. Full installation is also indicated through the distinct change in gradient, which is visualised in Figure 9 - i. e. the establishment of lid contact is presumed to stop the caisson penetration. Table 3 shows that total skirt penetration 
Table 3: Normalised penetration depths including settlements after during static loading

\begin{tabular}{|c|c|c|c|c|c|c|c|}
\hline \multirow{2}{*}{ Test name } & \multicolumn{2}{|c|}{ Penetration depth $z / L$} & \multirow[t]{2}{*}{ Test name } & \multicolumn{4}{|c|}{ Penetration depth $z / L$} \\
\hline & SWP & SI & & SWP & SI & SL & SUL \\
\hline INST-1-H-S & 0.478 & 0.930 & CYC-1-H-S & 0.562 & 0.967 & 0.971 & 0.968 \\
\hline INST-1-H-MS ${ }^{1}$ & 0.282 & 0.527 & CYC-1-H-MS ${ }^{1}$ & 0.306 & 0.618 & - & - \\
\hline INST-2-H-M & 0.363 & 0.803 & CYC-2-H-M & 0.515 & 0.867 & 0.873 & 0.870 \\
\hline INST-3-H-F & 0.478 & 0.941 & CYC-3-H-F & 0.471 & 0.913 & 0.926 & 0.924 \\
\hline INST-3-H-SF ${ }^{1}$ & 0.189 & 0.460 & - & - & - & - & - \\
\hline INST-4-L-M & 0.509 & 0.932 & CYC-4-L-M & 0.483 & 0.905 & 0.908 & 0.906 \\
\hline INST-5-L-F & 0.568 & 0.954 & CYC-5-L-F & 0.575 & 0.992 & 0.996 & 0.995 \\
\hline INST-5-L-SF & 0.459 & 0.937 & - & - & - & - & - \\
\hline INST-5-L-SF2 ${ }^{1}$ & 0.213 & 0.440 & - & - & - & - & - \\
\hline
\end{tabular}

depths of $z / L \leq 0.98$ were achieved in most tests. Thus, the occurrence of plug heave is likely.

Table 3 shows a similar settlement response for each caisson when the static vertical load was increased to $V / A=116 \mathrm{kPa}$. Since the sum of the calculated tip and measured skirt resistance $V / A \approx 88 \mathrm{kPa}$ is exceeded, the lid is expected to transfer stresses into the soil plug. This also indicates that partial or full lid contact is likely to be present in most tests regardless of the achieved skirt penetration depth.

Since different skirt penetration depths were achieved, a possible influence of the applied suction pressure is evaluated: The development of the normalised suction pressure during skirt penetration is presented in Figure 10 and follows an almost linear trend. Moreover, it appears to be independent of the pumping flow rate. This findings are reasonable since the measured values scatter around the predictions in accordance with Houlsby and Byrne (2005), using $\varphi_{p}=43^{\circ}, m=1.2, K \tan (\delta)=0.15$, and $k_{i} / k_{o}=1$.

The curves shown in Figures $9 \mathrm{a}$ and $9 \mathrm{~b}$ emphasise that a specific pumping flow rate leads to a respective caisson penetration velocity. Furthermore, a comparison between suction caisson installations for tests with CPT through the lid and installations for cyclic loading test show a similar response to the same pumping flow rate. This demonstrates that the suction caisson installation is reproducible in the centrifuge environment at $100 \mathrm{~g}$.

The test INST-1-H-S, INST-1-H-MS, CYC-1-H-S and CYC-1-H-MS were installed at relatively slow pumping flow rates. This results in a prototype caisson penetration rate of $\Delta \dot{z} \approx 0.18 \mathrm{~m} / \mathrm{h}$ in the beginning, which implies a prototype skirt penetration of two meters $(\Delta z / L=0.5)$ in $t \approx 11$ h of suction 
installation. The penetration rate immediately slowed down and tended to zero at a relative penetration depth of $\Delta z / L \approx 0.2$. Hence, the pumping flow rate was doubled at this point to avoid premature refusal (see Table 1).

Figures $9 \mathrm{c}$ and $9 \mathrm{~d}$ show the history of the normalised caisson penetration rate, which links the pumping flow rate to the suction pressure and the actual drainage conditions in accordance to Houlsby and Byrne (2005). A value of $\Delta \dot{z} A_{\text {caisson }} / \Delta \dot{z} A_{\text {pump }}=1$ implies no seepage losses, i. e. complete transferral of the pumping flow rate towards penetration of the suction caisson skirts; values less than 1 indicate seepage losses and hence less efficient suction installation. The normalised caisson penetration rate shown in Figure $9 \mathrm{c}$ and $9 \mathrm{~d}$ and therefore the suction pressure transferral rapidly decreased when a relatively slow pumping flow rate was applied. This behaviour indicates soil plug loosening due to the ongoing seepage flow and minimum caisson penetration rate. This implies that the skirt tip resistance is not reduced sufficiently, which eventually leads to premature refusal. Pivotal plug loosening is furthermore expected to be accompanied by a distinct drop in internal suction pressure. Since Figure 10 does not indicate this, insufficient reduction of the tip resistance is found to be the primary reason of the decreasing caisson penetration rate. However, loosening is indicated by a decreasing normalised caisson penetration rate presented in Figures $9 \mathrm{c}$ and 9d. Consequently, plug loosening is present to a certain extent, but does not trigger premature refusal.

In order to prevent refusal from insufficiently reduced skirt tip resistance, the pumping flow rate was doubled, which marks the point of the distinct change in gradient of the (normalised) caisson penetration rate. Based on the overall behaviour represented by Figure 9 it is presumed, that the increased pumping flow rate ensured the maintenance of the suction pressure and therefore enabled a successful installation. The test results presented in Figure 9 confirm and extend the conclusion of Bienen et al. (2018a) as a more comprehensive range of caisson penetration rates was achieved.

The results from tests INST-2-H-M, INST-4-L-M, CYC-2-H-M and CYC4-L-M plotted in Figure 9 represent caissons installed at a moderate pumping flow rate. A moderate pumping flow rate is similar to a prototype caisson installation of two meters of skirt length in $t \approx 5.5 \mathrm{~h}$. A nominally constant model caisson penetration rate of $\Delta \dot{z} \approx 0.1 \mathrm{~mm} / \mathrm{s}$ and a pumping flow rate transferral of $\Delta \dot{z} A_{\text {caisson }} / \Delta \dot{z} A_{\text {pump }} \approx 0.65$ to 0.85 was maintained for the majority of the suction installation process.

Those four moderate pumping flow rate tests provide insights into the fol- 
lowing aspects: Compared to the installations at lower pumping flow rates, a more uniform caisson penetration rate is achieved. Moreover, this indicates that a moderate pumping flow rate in those particular tests provides a certain balance between seepage flow and caisson penetration velocity that favoured complete caisson installations. Furthermore, the comparison of tests conducted in higher (INST-1-H-MS and CYC-1-H-MS) and lower (INST-4-L-M and CYC-4-L-M) effective sample permeabilities confirms the expectation that a lower effective permeability benefits the uniformity of the caisson penetration rate as less seepage flow occurs (see Figure 9).

Maximum caisson penetration rates between $\Delta \dot{z} \approx 0.23$ and $0.33 \mathrm{~mm} / \mathrm{s}$ were reached during the seven installations at relatively fast pumping flow rates. The seven caissons slowed down at a similar rate during the course of the installation. It is observed that more seepage losses occurred in tests INST-5-L-F and CYC-5-L-F that were performed in less permeable soil than in tests INST-3-H-F and CYC-3-H-F, which were conducted in a more permeable soil sample. This is contradictory to the behaviour observed in tests at moderate pumping flow rates. However, the considered caissons were successfully installed at slightly larger penetration depths compared to the ones at moderate pumping flow rate. This also holds for test INST-5-L-SF, which is the caisson that was installed successfully at the fastest pumping flow rate applied during the presented series of experiments.

It is summarised that slow pumping flow rates indicate to favour plug heave due to the presence of seepage flow and the absence of caisson penetration, which is consistent with Tran et al. (2004). The test results confirm that there is a certain minimum pumping flow rate above which suction installation is successful (Bienen et al., 2018a). The minimum pumping flow rate can be predicted in accordance with Houlsby and Byrne (2005). Furthermore, the evaluation of test results featuring a wide range of pumping flow rates does not indicate any systematic correlation between pumping flow rate and the suction pressure, the plug heave or the achieved penetration depths. Hence, it is presumed that the effect of the suction installation history is marginal.

\subsection{CPTs characterisation of the soil plug}

Four CPTs inside the installed suction caissons were conducted in addition to those presented in Stapelfeldt et al. (2018). All CPTs shown here 440 are renamed to facilitate comparison. The test discussed in Stapelfeldt et al. (2018) are marked with their previous names in addition. The CPTs inside 
the caisson are plotted together with the free field CPTs in Figure 11 for comparison. The free field CPTs were conducted in undisturbed soil at sites in the same soil samples.

Based on the CPTs discussed in Stapelfeldt et al. (2018) no clear influence of the suction installation on the cone tip resistance was found - although plug heave and loosening were considered as a probable result of fast installations. The additional tests provide a more comprehensive data base, which confirms the previous results. The CPT profiles obtained from test INST$3-\mathrm{H}-\mathrm{F}$ and INST-3-H-SF, which were installed at high pumping flow rates, show similar or higher cone tip resistance compared to test INST-3-H-M, which was referred to as Test 4 in Stapelfeldt et al. (2018).

The installation of the $L=80 \mathrm{~mm}$ model caisson in test INST-3-H-SF terminated at $z / L_{80}=0.46$, while test INST-3-H-F featuring the $L=40 \mathrm{~mm}$ model caisson was installed completely. Stapelfeldt et al. (2018) supposed that an increased cone resistance results from regaining strength of the soil plug after the suction installation within the confinement of the caisson skirt even without lid contact. These additional results confirm the conclusions of the previous study, because an increased cone resistance was measured inside completely (INST-3-H-SF) and partially (INST-3-H-F) installed caissons.

Furthermore, test INST-1-H-S shows a similar cone resistance compared to test INST-3-H-F before the gradient eventually changes close to a depth where the cone tip passes the skirt tip. Some plug heave was likely in test INST-1-H-S as discussed above. The respective CPT inside the caisson does not indicate a permanent impact on the plug state - e.g. the presence of significantly lower cone resistance that would indicate plug loosening and therefore heave. Based on the achieved penetration depth of $z / L=0.930$, it is likely that lid contact was present here. Consequently, the additional results confirm that lid contact rather than the suction installation dominate the stress state of the soil plug (Stapelfeldt et al., 2018) - i. e. the effect of the suction installation on the soil plug state is found to be marginal.

\subsubsection{Drained limiting capacities}

The estimated drained compressive bearing capacity of the caisson foundations in dense silica sand exceeds $R_{b}=6.5 \mathrm{MPa}$. Since the maximum compressive stress in this study is $V / A=128 \mathrm{kPa}$, only a fraction of the bearing capacity is expected to be mobilised. In contrast, the maximum drained tip resistance of $R_{t}=76 \mathrm{kPa}$ is exceeded during the static and cyclic loading sequences. The drained capacities were calculated in accordance to 
Larsen (2008) and Houlsby and Byrne (2005), respectively. The skirt fric480 tion capacity is estimated to be approximately $R_{s}=12 \mathrm{kPa}$ and has been validated by means of two drained pull-out tests, which are presented in Figure 12. The caisson was pulled out at a constant rate of $\dot{z}=0.001 \mathrm{~mm} / \mathrm{s}$. The maximum drained frictional capacity - i.e. the maximum skirt friction - is mobilised within $\Delta z / L \approx 0.002$ of upward displacement.

485

490

\subsubsection{Significance of the suction installation history}

The suction installation arguably does not influence the in-service performance despite possible changes of the soil sate during the suction installation - especially at extremely high or low pumping flow rates. The remaining uncertainties are addressed through three vertical cyclic loading test featuring 
slow, moderate and fast suction installation and cyclic loading around a low compressive average load.

Figure 13 shows the histories of five cyclic loading test, including the tests CYC-1-H-S, CYC-2-H-M, and CYC-3-H-F, which are considered here. The respective installation histories were presented in Figure 9a and 9c. Based on the previous discussion, it is expected that caissons with a more extreme installation history could show larger vertical displacements in Figure 13. A reduced relative density due to increased seepage flow could undermine the bearing capacity and the skirt friction. Though, the vertical displacement response of all three test lies within a narrow range. Based on the presented data it is concluded that the influence of the suction installation on the vertical load bearing behaviour indeed is marginal.

A further comparison of the two tests CYC-4-L-M and CYC-5-L-F, which featured a lower effective permeability but the same loading history, underpins this conclusion. The respective vertical displacement response illustrated in Figure 13 does not reveal a major influence due to the differing suction installation either. Including the previous experiments discussed in Bienen et al. (2018a), test were conducted in two different sands, at different average vertical loads and loading amplitudes as well as a comprehensive range of the effective permeabilities. None of these test provided evidence for a distinct influence of the suction installation on response to the vertical cyclic loading.

\subsubsection{Influence of the achieved penetration depth}

In test CYC-2-H-M a total skirt penetration depth of $z / L=0.867$ was achieved, which is the lowest value for a cyclic loading test in this study. Figure 13 shows that the largest displacements were reached in this test. This holds for both: The peak amplitude and the overall upward displacement in response to the applied vertical cyclic loading history. The comparison with test CYC-3-H-F, which had a skirt penetration of $z / L=0.913$, shows similar displacement overall but differences in particular around peak loading. Figure 14 illustrates the following aspects:

(1) The caisson in test CYC-2-H-M tends to settle in sequence two, while test $\mathrm{CYC}-3-\mathrm{H}-\mathrm{F}$ responds almost elastically at similar displacement amplitudes to the same cyclic load.

(2) The peak upward displacement during loading sequences three and four is significantly higher in test CYC-2-H-M, while the downward peaks 
show similar values. Eventually, this behaviour leads to a larger net uplift of CYC-2-H-M.

(3) LSQ 1 of the following loading set shows that test CYC-3-H-F responded almost elastic to small loading amplitudes. In contrast, the

555 caisson displacements in test CYC-2-H-M showed continuous net settlement over the following 15 to 20 load cycles, such that the results approached those of CYC-3-H-F.

Test CYC-2-H-M of this study achieved a skirt penetration depth of $z / L<0.867$, which is similar to several tests performed in Baskarp sand. Though, test CYC-2-H-M featured a different cyclic loading history extending the previous tests results. The results discussed in Bienen et al. (2018b) show that the caisson settles during cyclic loading under an average compressive load with a small cyclic amplitude that also extends into tension. It was also found that an average tensile stress cannot be tolerated as it leads to significant heave. Further evaluation of the results presented in Figures 13 and 14 shows that the highest peaks are often followed by successive settlement during the first few cycles of the following small loading amplitude sequence in presence of a compressive average stress. This holds for the tests conducted in high and low effective permeability soils in this study. Hence, this study confirms the occurrence of net settlement under low magnitude cyclic loading when the average stress is compressive.

It is likely that the lid loses contact - partially or completely - during high amplitude tensile loading in LSQ 3 and 4. This state is found to be indicated by the settlements occurring during the subsequent LSQ 1 . The vertical loads are transferred by the skirt friction and the tip resistance alone, resulting in significantly softer response in compression. This yields settlements as the tip bearing is expected to be partially drained. The lid presumingly touches down within $n \approx 20$ cycles leading to a stiffer response and decaying downward movement resulting in predominately elastic response to the low amplitude cyclic loading in LSQ 1.

It is furthermore observed that lower achieved penetration depths lead to significantly softer response to tensile loading. However, the net vertical displacements after each loading package do not differ considerably, because lower skirt penetration depth also leads to increased settlements in compression. Since the response to rapid loading heavily depends on the drainage regime, it is assumed that the skirt penetration and therefore the length of 
the drainage path plays a governing role. For instance, the initial drainage path in test CYC-3-H-F is approximately 5 to $10 \%$ longer than in it is in test CYC-2-H-M. Similarly the drainage path in test CYC-5-L-F is approximately 8 to $16 \%$ longer than it is in test CYC-4-L-M. Consistently, larger displacements can be observed in Figure 13 and 14. Hence, the presumed influence of the achieved skirt penetration depth on the load bearing behaviour manifests itself through the influence on the drainage regime.

\subsubsection{Effects of cyclic loading into tension}

All cyclic loading tests in this study featured a compressive average stress of $V / A=8 \mathrm{kPa}$. Tensile loads featured in each of the four sequences of the respective loading package. The response to the first three loading packages of test CYC-3-H-F and CYC-5-L-F was found to be representative for the other tests, with no indication of a permanent influence of the differing installation histories on the tests. The results presented in Figure 15 allow the following observations:

(1) Predominantly elastic response - i. e. nearly zero net displacement was measured during the first loading sequence (see also Figure 13). A peak tensile stress of $V / A=-8 \mathrm{kPa}$ was applied during each of the 1000 cycles, which corresponds to approximately $75 \%$ of the estimated drained frictional tensile capacity.

(2) Tension reached more than 2.5 times the drained frictional capacity during LSQ 2. Despite this, the response is primarily elastic with occasional small magnitude settlements. Significant and permanent vertical displacements only occur if the tensile load exceeded the drained frictional capacity by six times or more during LSQ 3 and 4 .

(3) Figure 15a and 15d show that the applied cyclic vertical loading history resulted in settlements and uplift in the higher and lower effective permeability sand, respectively. The cyclic loading of a caisson in more permeable soil results in net uplift after each loading package. Furthermore, Figure 15a indicates that the initial response to tensile loading is stiffer than it is during subsequent cyclic loading. However, there is no indication of considerable accumulative reduction of stiffness. In less permeable soil, the caisson settled during the first few loading packages before it started to move upwards, similar to the suction caisson embed- 
ded in more permeable soil (see Figure 15d). The unloading stiffness was considerably lower than the initial stiffness in this case.

Observations (1) and (2) confirm findings from previous work and therefore underpin that a suction caisson can withstand tensile loads exceeding the drained frictional capacity without permanent upward displacement. Observation (3) adds to the previous findings, where similar vertical cyclic loading resulted in net settlements in tests featuring an effective permeability that was three times lower than the lowest in this study (Bienen et al., 2018a). Thus, it is concluded that there must be a certain maximum effective permeability determining net uplift or net settlement response. This threshold depends on the in situ drainage regime, which is determined by the loading rate and the granular characteristics of the soil.

\subsubsection{Influence of the drainage regime on the load bearing mechanism}

A comparison of vertical displacements, loading, excess pore pressure and stresses is given in Figure 16. The total stresses and excess pore pressures were measured at the lid invert. Figure $16 \mathrm{c}$ and $16 \mathrm{~d}$ show that the total stresses recorded at the lid invert are completely carried by the excess pore pressure. Thus, the response is considered to be undrained at the lid invert. Excess pore pressure accumulation is not observed as the excess pore pressure cycles with the total stresses. Figure 15c confirms this observation, because the gradient of the relation between excess pore pressure and total stresses is approximately one. Figure $15 \mathrm{~b}$ shows similar relations of applied vertical load with the total stress at the lid invert. Since test CYC-3-H-F and CYC5 -L-F show similar behaviour, it is reasonable to assume that the amount of load transferred to the lid is independent of the effective permeability within the investigated range.

Bienen et al. (2018b) emphasised the importance of the drainage regime on the vertical displacement response to cyclic loading. The magnitude of vertical net displacement after the three loading packages is approximately twice as large in test CYC-3-H-F as it was in a similar test conducted in Baskarp sand. Baskarp sand is slightly less permeable and tends to dilate at a higher rate than fine silica sand. Thus, excess pore pressures and therefore the resistance to tensile loading is mobilised earlier resulting in lower magnitude caisson displacements. It is noted that this principle includes that the cavitation limit of Baskarp sand is lower compared to fine silica sand. 
Consequently, the same loading regime can result in smaller or larger caisson displacements depending on the onset of cavitation.

Figure $16 \mathrm{a}$ and $16 \mathrm{~b}$ show that a certain amount of the vertical stresses is carried by the skirt friction. Furthermore, the skirt tip appears to bear a considerable portion of the vertical load in compression. The displacements in Figure 15d show a hard capped mobilisable effective resistance of $V^{\prime} / A \approx 15 \mathrm{kPa}$ in tension and a flattening curve in compression once the drained frictional capacity is exceeded. This suggests that the skirt friction is fully mobilised at smaller relative displacements than the lid resistance. In addition, the maximum load transferred in compression is considerably higher than the sum of the skirt and tip resistance, which reinforces the assumption of presence of lid contact in compression. The tests presented in Bienen et al. (2018b) show similar repose to the same loading regime in Baskarp sand.

The comparison of tests performed in higher (Figure 16a and 16c) and lower (Figure 16b and 16d) effective permeability soil samples demonstrates a significant difference in magnitude of vertical displacements. The drainage regime governs the response to cyclic loading in the presented tests, i. e. the uplift velocity and the effective permeability determine the excess pore pressures around the foundations and thus critically influence the suction caisson behaviour.

\section{Simplified prediction method}

Since it was concluded that the drainage regime governs the vertical load bearing behaviour, it is reasonable to employ the approach introduced by Houlsby and Byrne (2005) and Houlsby et al. (2005) for the development of a simplified prediction method of the response of suction caissons under vertical cyclic loading. The presented approach includes predictions of uplift and settlements in tension and compression, respectively. Classical consolidation theory is utilised to estimate vertical displacements in compression (Boussinesq, 1885; Terzaghi and Fröhlich, 1936). Positive values indicate compression and displacements in the downward direction, whereas negative values represent tension and displacements in the upward direction in accordance with the remainder of the paper, although this may differ from the nomenclature in the original references. 


\subsection{General concept and basic assumptions}

The presented method utilises different equations for different loading states. Therefore, the actual loading state is to be checked at the beginning of each calculation step. This is done as follows: First, the current load is evaluated as being compressive or tensile. Second, loading or unloading are differentiated. Consequently four different loading stages are possible: (1) compressive loading, (2) compressive unloading, (3) tensile loading, (4) tensile unloading.

The presented calculation method follows the principles as laid out by Houlsby and Byrne (2005) and Houlsby et al. (2005). In addition, several assumptions were made and specifications were adopted. The load bearing behaviour is simplified as the calculation of the tip resistance is neglected. This assumption is considered to be reasonable since full lid contact is expected, which implies that the tip resistance carries only a marginal portion of the load compared to the lid under the assumption of full lid contact. Furthermore, it is assumed that the soil at the skirt tip is disturbed during cyclic loading. The effective skirt friction is calculated in each time step under consideration of the actual excess pore pressure distribution. Changes in effective plug permeability during tensile loading and unloading are accounted for following the principles set out by Houlsby and Byrne (2005). Furthermore, the onset of liquefaction and cavitation due to rapid tensile loading is taken into account in accordance with Houlsby et al. (2005).

\subsection{Calculations scheme for compression}

The compressive differential stresses $\Delta \sigma_{v, j}$ can be calculated from the following equation (Boussinesq, 1885):

$$
\Delta \sigma_{v, j}=\frac{V-F_{\text {in }}-F_{\text {out }}}{\frac{\pi D_{o}^{2}}{4}} \cdot\left(1-\frac{1}{\left(\left(\frac{D}{2 z_{j}}\right)^{2}+1\right)^{\frac{3}{2}}}\right)
$$

where $V$ is the vertical load. $F_{\text {out }}$ and $F_{\text {out }}$ are the internal and external skirt friction. The differential stresses are calculated for a finite number of fictive soil layers located in their respective depths $z_{j}$ below the caisson lid, which are enumerated through the index $j$. According to Terzaghi and Fröhlich (1936), the coefficient of consolidation $c_{v}$ and the dimensionless time factor $\tau$ yield the degree of consolidation $\mu$ : 


$$
\mu=2 \cdot \sqrt[2]{\frac{\tau}{\pi}}=2 \cdot \sqrt[2]{\frac{c_{v} t}{\pi L^{2}}}=2 \cdot \sqrt[2]{\frac{E_{s} k_{i} t}{\gamma_{w} \pi L^{2}}}
$$

The dimensionless vertical displacement $\Delta z / L$ resulting from compressive loading or unloading can be obtained from the following equation:

$$
\frac{\Delta z}{L}=\frac{\mu}{L} \cdot \frac{\sum_{0}^{j} d_{j} \Delta \sigma_{v, j}}{E_{s}}
$$

where $d_{j}$ is the thickness of the respective soil layer and $E_{s}$ represents the stiffness modulus, acknowledging that the actual soil stiffness depends on the loading history and direction.

\subsection{Calculations scheme for tension}

Tensile load is carried through the internal $F_{\text {in }}$ and external $F_{\text {out }}$ skirt friction and the differential pressure $s$ at the lid invert (Houlsby et al., 2005):

$$
V^{\prime}=F_{\text {in }}+F_{\text {out }}+\frac{\pi D_{i}^{2}}{4} \cdot s
$$

Differential pressure is mobilised if the applied load exceeds the frictional capacity. The internal and external skirt friction are obtained from Equations 5 and 6 , which take the influence of the seepage flow into account. This approach was originally proposed by Houlsby and Byrne (2005):

$$
\begin{gathered}
F_{\text {in }}=\frac{\pi L^{2}}{2} \cdot\left(\gamma^{\prime}-\frac{(1-a) s}{L}\right) D_{i}(K \tan \delta)_{i} \\
F_{\text {out }}=\frac{\pi L^{2}}{2} \cdot\left(\gamma^{\prime}+\frac{a s}{L}\right) D_{o}(K \tan \delta)_{o}
\end{gathered}
$$

The pressure factor $a$ was determined from numerical calculations (Houlsby and Byrne, 2005). The results can be recalculated by means of an analytical approximation:

$$
\begin{gathered}
a=\frac{a_{1} k_{f}}{\left(1-a_{1}\right)+a k_{f}} \\
a=a_{1}=c_{0}-c_{1}\left(1-\exp \left(-\frac{L}{c_{2} D}\right)\right)
\end{gathered}
$$


where $k_{f}=k_{i} / k_{o}$ represents the ratio between the effective internal $k_{i}$ and external $k_{o}$ effective permeability. The coefficients $c_{0}=0.45$ and $c_{1}=0.36$ and $c_{2}=0.48$ are taken from Houlsby and Byrne (2005). Equation 5 to 8 were originally developed for the prediction of the suction pressure required for the caisson installation in sand. Since the hydraulic mechanisms during tensile loading are comparable to those that are present during the suction installation. This approach was deemed applicable. However, a reversed seepage flow direction is present during unloading. Thus, the modified equation 10 is required.

$$
\begin{gathered}
F_{\text {in }, u l}=\frac{\pi L^{2}}{2} \cdot\left(\gamma^{\prime}+\frac{a s}{L}\right) D_{i}(K \tan \delta)_{i} \\
F_{\text {out }, u l}=\frac{\pi L^{2}}{2} \cdot\left(\gamma^{\prime}-\frac{(1-a) s}{L}\right) D_{o}(K \tan \delta)_{o}
\end{gathered}
$$

\subsubsection{Small displacement rates}

The Equations proposed by Houlsby and Byrne (2005) and Houlsby et al. (2005) were combined and rearranged so that the differential pressure can be obtained:

$$
\begin{gathered}
s=\frac{V^{\prime}-A}{B+C} \\
A=\frac{\gamma^{\prime} \pi L^{2}}{2}\left(D_{i}(K \tan \delta)_{i}+D_{o}(K \tan \delta)_{o}\right) \\
B=\frac{\pi D_{i}^{2}}{4} \\
C=\frac{\pi L}{2}\left(D_{i}(K \tan \delta)_{i}(1-a)+D_{o}(K \tan \delta)_{o}(a)\right)
\end{gathered}
$$

The presented equations are applicable for relatively small displacement 750 rates during tensile loading, which supposes the absence of liquefaction and cavitation. The calculation of the differential pressure during tensile unloading requires the following equation.

$$
C_{u l}=\frac{\pi L}{2}\left(D_{i}(K \tan \delta)_{i}(a)+D_{o}(K \tan \delta)_{o}(1-a)\right)
$$




\subsubsection{Large displacement rates}

Small displacements are considered to be exceeded as soon as cavitation

755 dent from each other or simultaneously. Thus, each possible state is to be considered (Houlsby et al., 2005).

The differential pressure obtained for small displacement rates is limited by the cavitation pressure $s_{c a v}=p_{a}(1-f)+\gamma_{w} h_{w}-$ i. e. the sum of the 760 atmospheric and the hydrostatic pressures. The onset of plug liquefaction is reached as soon as the differential pressure exceeds $\gamma^{\prime} L /(1-a)$ (Houlsby et al., 2005). Thus, the differential pressure can be calculated from from the following equation before the cavitation limit is reached.

$$
s=s_{u l}=\frac{V^{\prime}}{\left.\frac{\pi D^{2}}{4}\left(1+\frac{2 L}{D}(K \tan \delta)_{o}\right)\right)}
$$

\subsubsection{Calculation of vertical displacements}

Once a differential pressure inside the caisson is present, seepage flow will occur. The inflow of water and therefore, the volume change of the plug can be obtained from Darcy's law. Based on the findings by Houlsby and Byrne (2005) and Houlsby et al. (2005), the vertical displacement rate can be calculated as:

$$
\dot{z}=\frac{F k_{i} s}{\frac{\pi D_{i}}{4} \gamma_{w} L}
$$

where $F$ is the dimensionless flow factor for caissons with an aspect ratio of $0.1 \leq L / D \leq 0.8$, which is given through the following equation:

$$
F=\frac{(1-a) \pi k_{f}}{4 \cdot \frac{L}{D}}
$$

In contrast to Houlsby et al. (2005), $k_{i}$ instead of $k_{o}$ is employed in Equation 17. This is reasonable for small displacement rates, since $k_{f}=1$ was found to be reasonable here. Analogue to Houlsby et al. (2005) Equation 17 is also utilised when large displacement rates occur. Since the limitation of laminar flow in Darcy's law might be exceeded, the dimensionless flow factor is modified. The onset of liquefaction includes a significant increase in effective permeability. Thus, the dimensional flow factor during liquefaction is estimated by means of Equation 18, but it is recommended to consider 
Table 4: Input parameters for the simplified prediction method

\begin{tabular}{|c|c|c|c|}
\hline \multicolumn{2}{|c|}{ Parameter } & CYC-3-H-F & CYC-5-L-F \\
\hline$L$ & $(\mathrm{~m})$ & 4 & 4 \\
\hline$D$ & $(\mathrm{~m})$ & 8 & 8 \\
\hline$t$ & $(\mathrm{~cm})$ & 5 & 5 \\
\hline$(K \tan \delta)_{o}$ & $(-)$ & 0.15 & 0.15 \\
\hline$(K \tan \delta)_{i}$ & $(-)$ & 0.15 & 0.15 \\
\hline$E_{s}$ & $(\mathrm{MPa})$ & 138 & 138 \\
\hline$\gamma^{\prime}$ & $(\mathrm{kPa})$ & 10.5 & 10.5 \\
\hline$\gamma_{w}$ & $(\mathrm{kPa})$ & 10 & 10 \\
\hline$k_{o}$ & $(\mathrm{~m} / \mathrm{s})$ & $1 \cdot 10^{-5}$ & $3.3 \cdot 10^{-5}$ \\
\hline$k_{f}$ & $(-)$ & 1 & 1 \\
\hline$k_{f, L}$ & $(-)$ & $3.5-4$ & $4.5-5$ \\
\hline$s_{\text {cav }}$ & $(\mathrm{kPa})$ & 100 & 100 \\
\hline
\end{tabular}

Once the displacement rate is calculated, the normalised vertical displacement can be estimated through the multiplication with the corresponding differential time $\Delta t$ :

$$
\frac{\Delta z}{L}=\frac{\dot{z} \cdot \Delta t}{L}
$$

\subsection{Retrospective calculation of cyclic loading tests}

The utilisation of the simplified prediction method requires a total of twelve input parameters, which are summarised in Table 4. This includes the caisson dimensions and internal and external skirt friction factors. These values can be obtained from literature or testing. Here they were determined from drained pull-out tests. Furthermore, soil parameters - i. e. $E_{s}, \gamma^{\prime}$ and $k_{0}$ - and the cavitation limit $s_{\text {cav }}$ need to be known. Because of the cyclic and the previous static loading an increased soil stiffness is expected. Here $E_{s}$ was estimated from the re-loading stiffness obtained from oedometer tests. In addition, the $k_{f}$ ratio for small loading rates and a value for $k_{f, L}$ is required for calculations at the onset of liquefaction. Based on the results of this study and the likelihood of a significant loss of effective permeability, upper bound values for $k_{f, L}$ from Houlsby and Byrne (2005) were deemed to be suitable.

Figure 17 shows a section of the vertical displacement history. The third 
and fourth loading package are presented, because these were found to be representative of the general behaviour. The original centrifuge test data presented in Figure 12 is plotted in the background covered by the calculated curves. It is demonstrated that the simplified calculations provide in an appropriate prediction of the overall behaviour, with the predominately elastic response to the loading sequences one and two matching the magnitude of the experimental results. Once higher loading amplitudes are applied net heave is predicted, which is consistent with the experimental results.

The net heave resulting from each loading package is believed to mainly result of two factors: The probably already mobilised skirt tip resistance and the changing seepage flow regime during tensile unloading, which is accompanied by an regain of the effective permeability. Since the degree of mobilisation of the tip resistance in disturbed soil is considered to be negligible, it is assumed that a decreasing effective permeability is the pivotal factor here. This is taken into account through the utilisation of the lower bound values for $k_{f, L}$ given in Table 4 during tensile unloading at the onset of liquefaction.

This assumption is a reasonable albeit major simplification. However, it enables an appropriate back-calculation of the experimental results. Furthermore, it is shown that the presented method provides suitable results for the lower and upper bound permeabilities. This also emphasises the importance of accurate knowledge of the in situ effective permeability and possible changes related to soil-structure interaction. Thus, the investigation of lower and upper bound permeabilities is recommended. Furthermore, it is suggested to reduce the liquefaction limit in the prediction by a few percent, to gain an insight into the probability of sudden occurrence of significantly softer response to tensile loading.

\section{Concluding remarks}

This paper discusses results of two parallel series of centrifuge tests investigating the suction caisson installation and the behaviour under vertical cyclic loading into tension in sand. The post installation condition of the soil plug was investigated by means of CPTs through the caisson lid in one series. The second series featured cyclic loading tests with the purpose of the investigation of a possibly permanent effect of the suction installation an the load bearing behaviour. Furthermore, the importance of the overall drainage regime on the vertical load bearing behaviour was targeted through 
the cyclic loading tests. The results add to the existing database and lead to 835 a simplified method, which enables the prediction of vertical displacements of caisson foundations under vertical cyclic loading. The experiments support the following findings:

(1) The pumping flow rate applied during suction caisson installation was not found to influence the soil plug, as shown by cone tip resistance profiles obtained inside the caisson following installation.

(2) The soil plug state is dominated by the lid contact and confinement inside the skirt once the suction installation is completed. Hence, the role of the pumping flow rate applied during suction caisson installation is marginal.

(3) The installation history was found not to significantly influence on the behaviour under vertical cyclic loading into tension. However, the achieved skirt penetration depth and therefore the length of the drainage path affects the response to cyclic loading in the tests performed in this study.

(4) The excess pore pressures at the lid invert cycles with the applied stresses and there is no indication of accumulative effects. Undrained behaviour at the lid invert is concluded as the total stresses transferred to the lid are entirely carried by excess pore pressure. The magnitude of the respective vertical displacement was found to be highly depended on the in situ effective soil permeability.

(5) When subjected to tensile loads during cyclic loading, the caisson foundation mobilised resistance beyond the drained frictional capacity without permanent displacement - i. e. predominately elastic response in load sequence one and two - in this study. In contrast, the response to high magnitude tensile loads during load sequence three and four featured substantial permanent net heave, which is expected to be critical for the serviceability of an OWT.

(6) A simplified prediction method is presented for the response of suction caissons under vertical loading. This approach includes compressive and tensile loading and unloading, and the occurrence of liquefaction and cavitation. The comparison with measured data from centrifuge 
tests with predictions of vertical caisson displacements due to cyclic loading in dense sand highlights good agreement.

The results discussed in this paper showed no permanent influence of the

870

Andersen, K.H., Murff, J.D., Randolph, M.F., Clukey, E.C., Erbrich, C.T., Jostadt, H.P., Hansen, B., Aubeny, C., Sharma, P., Supachawarote, C., 2005. Suction Anchors for Deepwater Applications, in: Proc. International 
Symposium on Frontiers in Offshore Geotechnics IS-FOG, Int. Symp. On Frontiers in Offshore Geotechnics. pp. 3-30.

Bienen, B., Cassidy, M.J., 2006. Advances in the three-dimensional fluidstructure-soil interaction analysis of offshore jack-up structures. Marine Structures 19, 110-140. doi:10.1016/j.marstruc.2006.09.002.

Bienen, B., Klinkvort, R.T., O’Loughlin, C.D., Zhu, F., Byrne, B.W., 2018a. Suction caissons in dense sand, part I: Installation, limiting capacity and drainage. Géotechnique 68, 937-952. doi:10.1680/jgeot.16.P.281.

Bienen, B., Klinkvort, R.T., O’Loughlin, C.D., Zhu, F., Byrne, B.W., 2018b. Suction caissons in dense sand, part II: Vertical cyclic loading into tension. Géotechnique 68, 953-967. doi:10.1680/jgeot.16.P. 282.

Boussinesq, M.J., 1885. Application des potentiels et d'analysea l'étude de l'équilibre et du mouvement des solides élastiques, avec des notes étendues sur divers points de physique mathématique. Gauthier-Villard imprimeur libraire., Paris.

Bye, A., Erbrich, C.T., Rognlien, B., 1995. Geotechnical Design of Bucket Foundations, in: Offshore Technology Conference, pp. 869-883. doi:10. 4043/7793-MS.

Byrne, B.W., Houlsby, G.T., 2002. Experimental Investigations of Response of Suction Caissons to Transient Vertical Loading. Journal of Geotechnical and Geoenvironmental Engineering 128, 926-939. doi:10.1061/(ASCE) 1090-0241 (2002) 128:11(926).

Byrne, B.W., Houlsby, G.T., 2004. Experimental Investigations of the Response of Suction Caissons to Transistent Combined Loading. Journal of Geotechnical an Geoenvironmental Engineering 130, 240-253. doi:10. 1061/(ASCE) 1090-0241 (2004) 130:3(240).

Cox, J.A., O’Loughlin, C.D., Cassidy, M.J., Bhattacharya, S., Gaudin, C., Bienen, B., 2014. Centrifuge study on the cyclic performance of caissons in sand. International Journal of Physical Modelling in Geotechnics 14, 99-115. doi:10.1680/ijpmg.14.00016.

DOW, 2002. Methocel cellulose ethers: Technical handbook. United States of America. 
Eide, O., Andersen, K.H., 1984. Foundation engineering for gravity structures in the northern North Sea. volume nr. 154 of Publikasjon $=$ Publication / Norges geotekniske institutt. Norges geotekniske institutt, Oslo [Norway].

Finnie, I., Randolph, M.F., 1994. Punch-through and liquefaction induced failure of shallow foundations on calcareous sediments, in: Seventh International Conference on the Behaviour of Offshore Structures, Pergamon, United Kingdom. pp. 217-230.

Houlsby, G., Kelly, R., Byrne, B., 2005. The tensile capacity of suction caissons in sand under rapid loading, in: Gourvenec, S., Cassidy, M. (Eds.), Frontiers in offshore geotechnics. Taylor \& Francis, London. Balkema proceedings and monographs in engineering, water and earth sciences, pp. 405-410. doi:10.1201/NOE0415390637.ch40.

Houlsby, G.T., Byrne, B.W., 2005. Design procedures for installation of suction caissons in sand. Geotechnical Engineering 158, 135-144. doi:10. 1680/geng.158.3.135.66297.

Houlsby, G.T., Kelly, R.B., Huxtable, J., Byrne, B.W., 2006. Field trials of suction caissons in sand for offshore wind turbine foundations. Géotechnique 56, 3-10. doi:10.1680/geot.2006.56.1.3.

House, A.R., 2002. Suction Caisson Foundations for Buoyant Offshore Facilities. Dissertation. The University of Western Australia. Perth.

Ibsen, L.B., 2008. Implementation of a New Foundations Concept for Offshore Wind Farms, in: Proc. NordiskGeoteknikermøte nr. 15, pp. 1-15.

Kelly, R.B., Houlsby, G.T., Byrne, B.W., 2006a. A comparison of field and 955 laboratory tests of caisson foundations in sand and clay. Géotechnique 56, $617-626$.

Kelly, R.B., Houlsby, G.T., Byrne, B.W., 2006b. Transient Vertical Loading of Model Suction Caissons in a Pressure Chamber. Géotechnique , 665675doi:10.1680/geot.2006.56.10.665.

Kim, D.S., Lee, S.T., Kim, J.H., 2016. Centrifuge model tests on installation of suction caissons in sand, in: The 6th Japan-Korea Geotechnical Workshop, pp. 73-77. doi:10.3208/jgssp.v04.k05. 
Larsen, K.A., 2008. Static Behaviour of Bucket Foundations. Dissertation. Aalborg University. Aalborg.

965

Lehane, B.M., Liu, Q.B., 2013. Measurement of Shearing Characteristics of Granular Materials at Low Stress Levels in a Shear Box. Geotechnical and Geological Engineering 31, 329-336.

Ragni, R., Bienen, B., Stanier, S.A., Cassidy, M.J., O’Loughlin, C.D., 2018. Visualisation of mechanisms governing suction bucket installation in dense sand, in: Physical Modelling In Geotechnics, Volume 1. CRC Press, [S.l.], pp. 651-565.

Ragni, R., Bienen, B., Stanier, S.A., O’Loughlin, C.D., Cassidy, M.J., 2019. Observations during suction bucket installation in sand. International Journal of Physical Modelling in Geotechnics , 1-49doi:10.1680/jphmg . 18.00071 .

Randolph, M.F., Gaudin, C., 2017. Genesis of the national geotechnical centrifuge facility - a 30 year perspective. Australian Geomechanics Journal $52,1-14$.

Randolph, M.F., Jewell, R.J., Stone, K.J.L., Brown, T.A., 1991. Establishing a new Centrifuge Facility, in: Ko, H.J., McLean, F.G. (Eds.), Proc. International Conference Centrifuge 1991, Belkema, Rotterdamm. pp. 3-9.

Senders, M., 2008. Suction Caissons in Sand as Tripod Foundations for Offshore Wind Turbines. Phd thesis. The University of Western Australia. Perth.

Senders, M., Randolph, M.F., 2009. CPT-Based Method for the Installation of Suction Caissons in Sand. J. Geotech. Geoenviron. Eng. (Journal of Geotechnical and Geoenvironmental Engineering 135, 14-25.

Stapelfeldt, M., Bienen, B., Grabe, J., 2018. Centrifuge tests investigating the effect of suction caisson installation in dense sand on the state of the soil plug, in: Physical Modelling In Geotechnics, Volume 1. CRC Press, [S.l.], pp. 669-674.

Tan, T.S., Scott, R.F., 1987. Discussion: Centrifuge scaling considerations for fluid-particle systems. Géotechnique 37, 131-133. doi:10.1680/geot. 1987.37.1.131. 
995

Taylor, R.N., 2011. Geotechnical centrifuge technology. Taylor \& Francis, London.

Terzaghi, K., Fröhlich, O.K., 1936. Theorie der Setzung von Tonschichten: eine Einführung in die analytische Tonmechanik. Deuticke, Leipzig and Wien.

1000

Tjelta, T., 2015. The suction foundation technology, in: Meyer, V. (Ed.), Frontiers in offshore geotechnics III. CRC Press/Balkema, Leiden, Netherlands, pp. 85-93. doi:10.1201/b18442-6.

Tjelta, T.I., 1995. Geotechnical Experience from the Installation of the Europipe Jacket with Bucket Foundations, in: Offshore Technology Confer1005 ence, pp. 897-908. doi:10.4043/7795-MS.

Tran, M.N., 2005. Installation of Suction Caissons in Dense Sand and the Influence of Silt and Cemented Layers. PhD thesis. The University of Sydney. Sydney.

Tran, M.N., Randolph, M.F., 2008. Variation of Suction Pressure During 1010 Caisson Installation in Sand. Géotechnique 58, 1-11. doi:10.1680/geot. 2008.58.1.1.

Tran, M.N., Randolph, M.F., Airey, D.W., 2004. Experimental Study of Suction Installation of Caissons in Dense Sand, in: Proceedings of the 23rd International Conference on Offshore Mechanics and Arctic Engineering 1015 


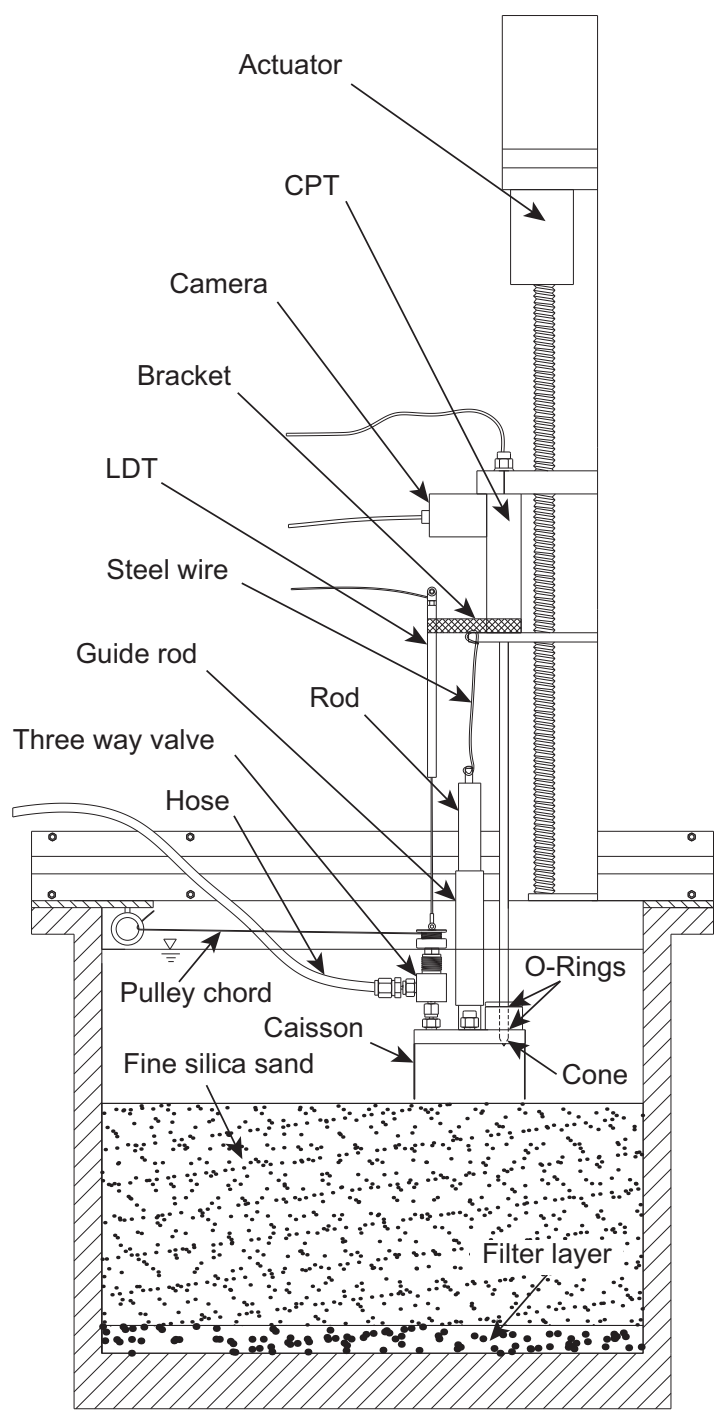

Figure 2: Centrifuge test set-up for suction caisson installation followed by a CPT through the lid. 


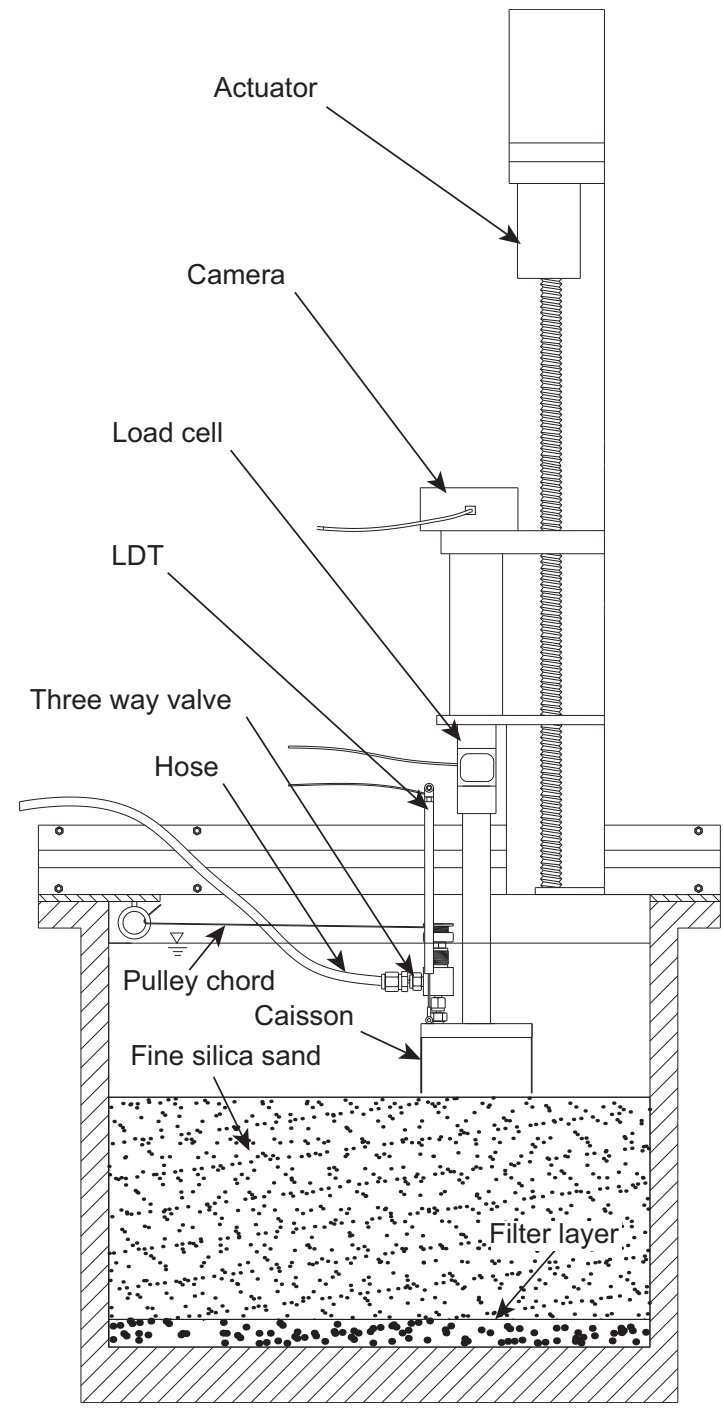

Figure 3: Centrifuge test set-up for suction caisson installation followed by a cyclic loading test. 


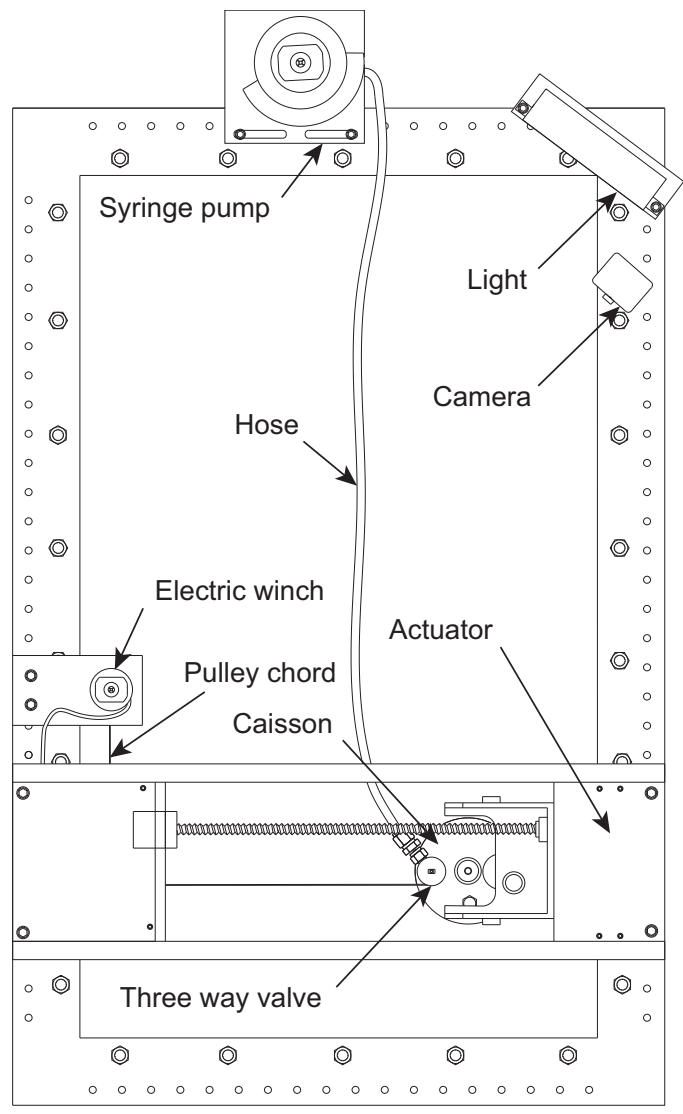

Figure 4: Top view on the centrifuge test arrangement.

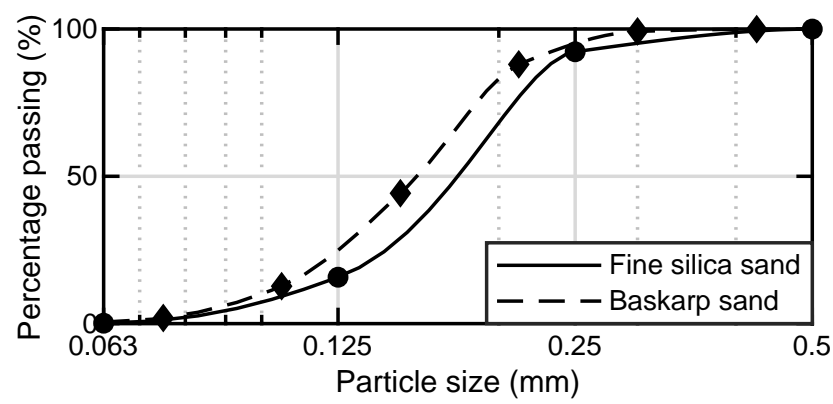

Figure 5: Particle size distributions. 


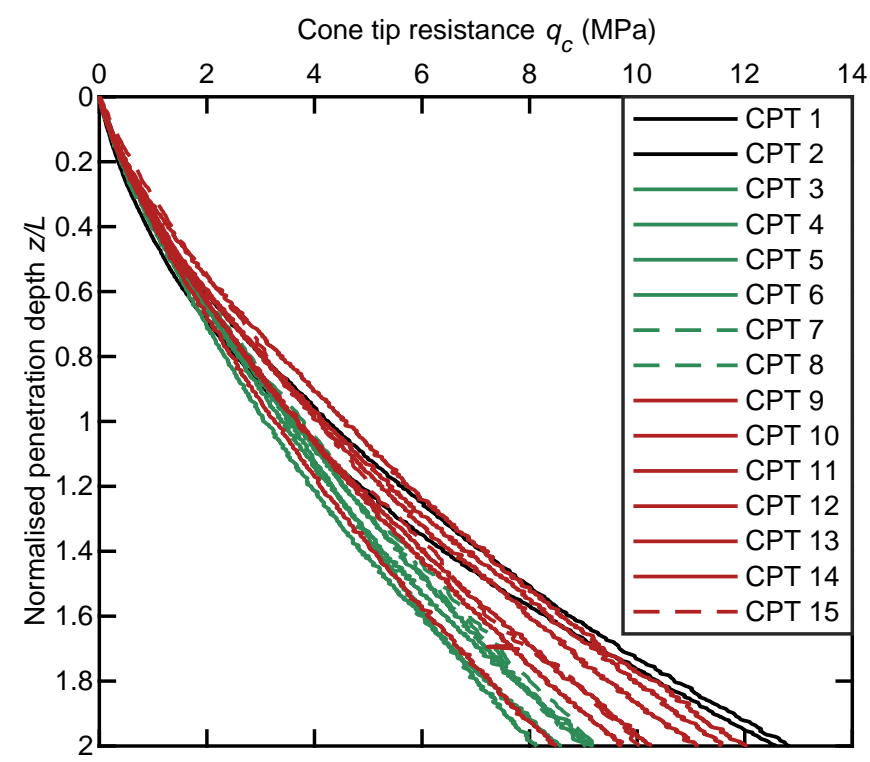

Figure 6: CPT profiles from soil sample no. 1 (CPT 1 \& 2), sample no. 2 (CPT 3 - 8), and sample no. 3 (CPT 9 - 15).

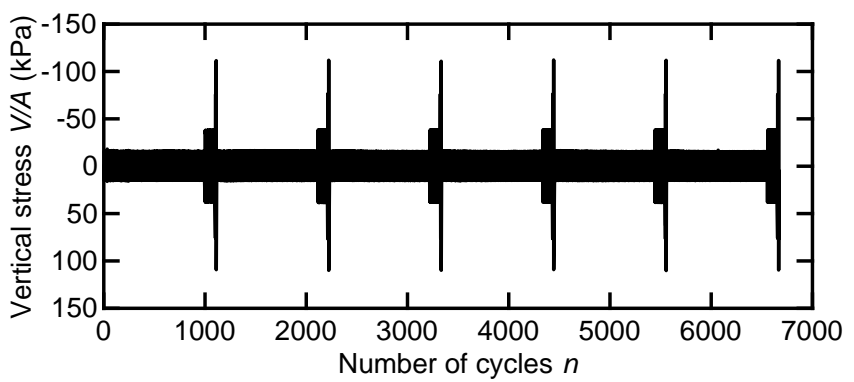

Figure 7: History of six vertical cyclic loading stets 


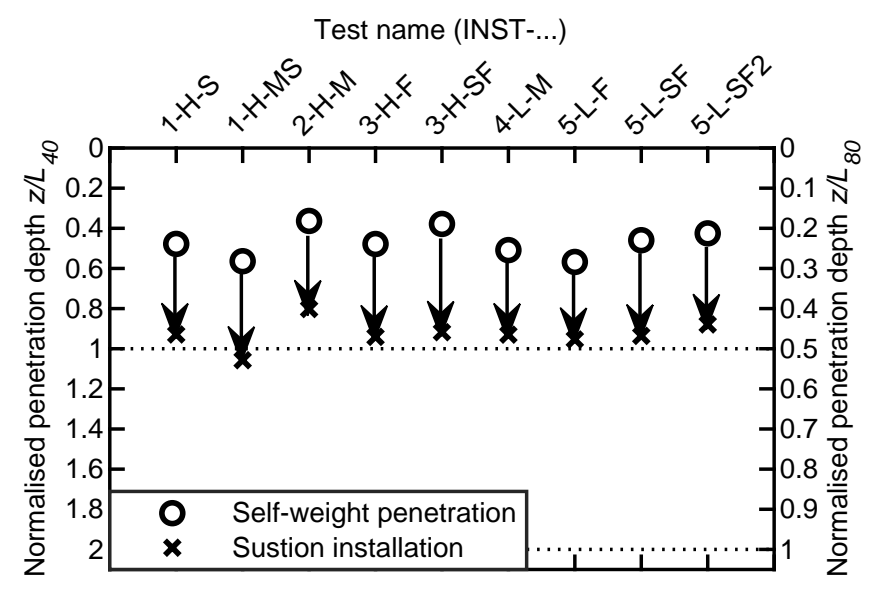

(a)

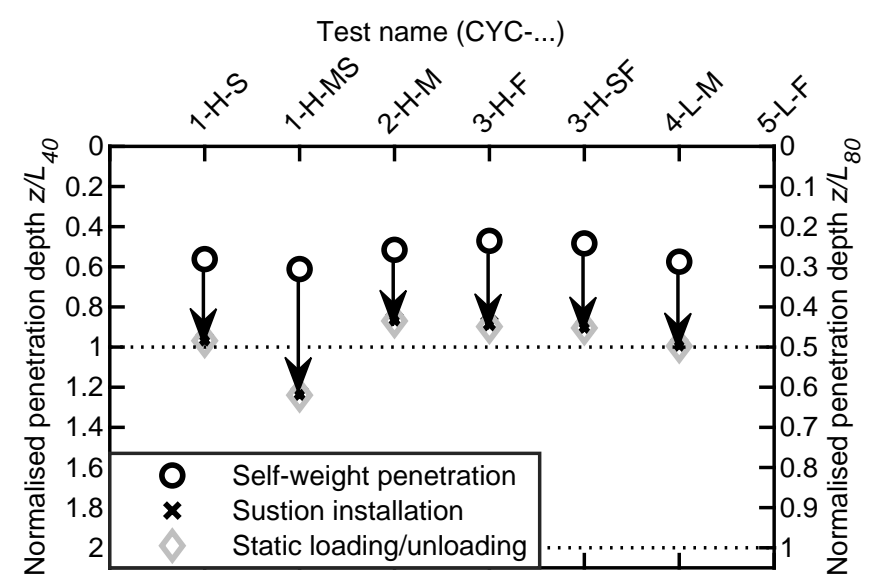

(b)

Figure 8: Normalised penetration depths of tests with CPT (a) and cyclic loading (b) 


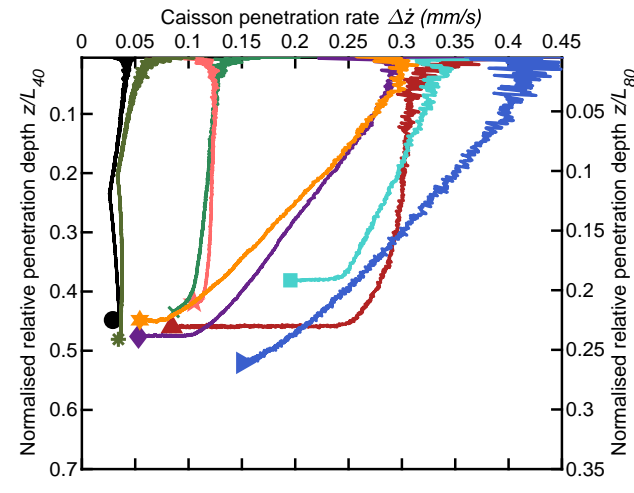

(a)

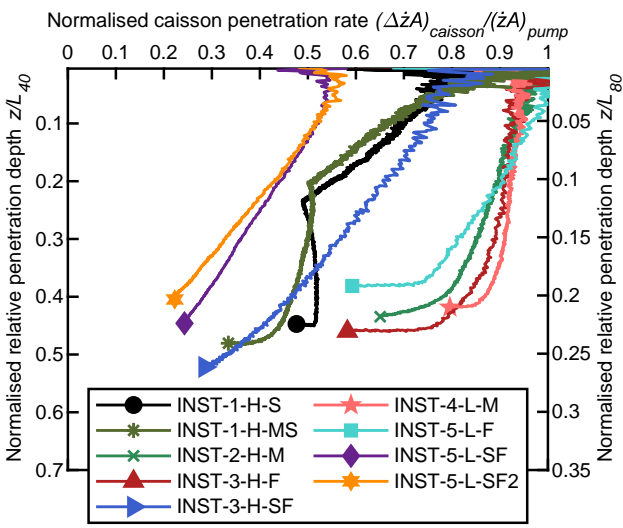

(c)

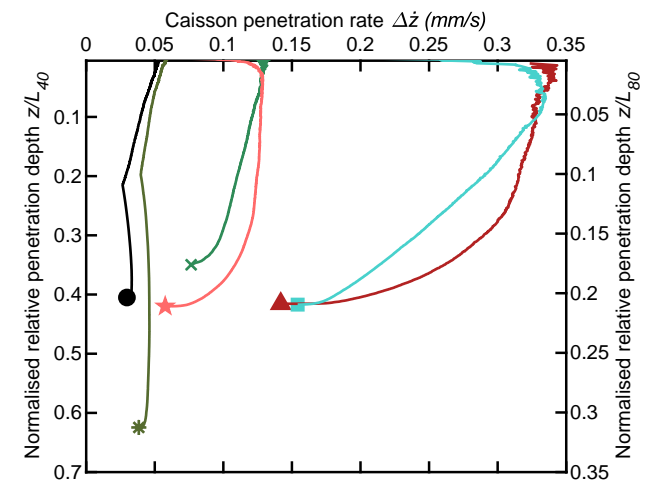

(b)

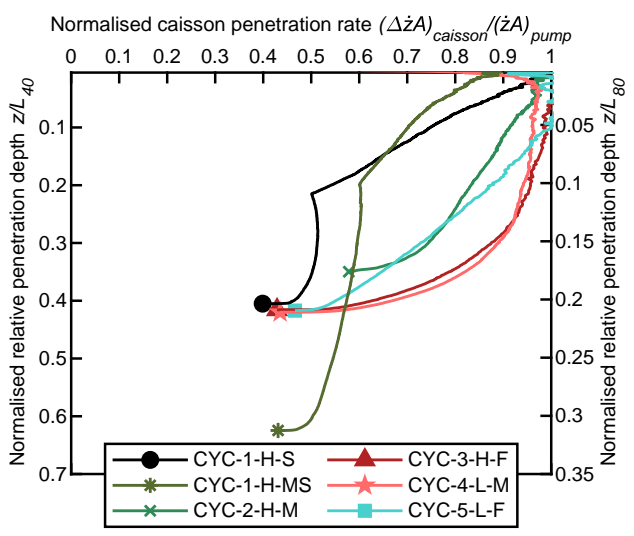

(d)

Figure 9: History of caisson penetration rates and normalised caisson penetration rates during installations for CPTs through the lid (a/c) and cyclic loading tests (b/d). 


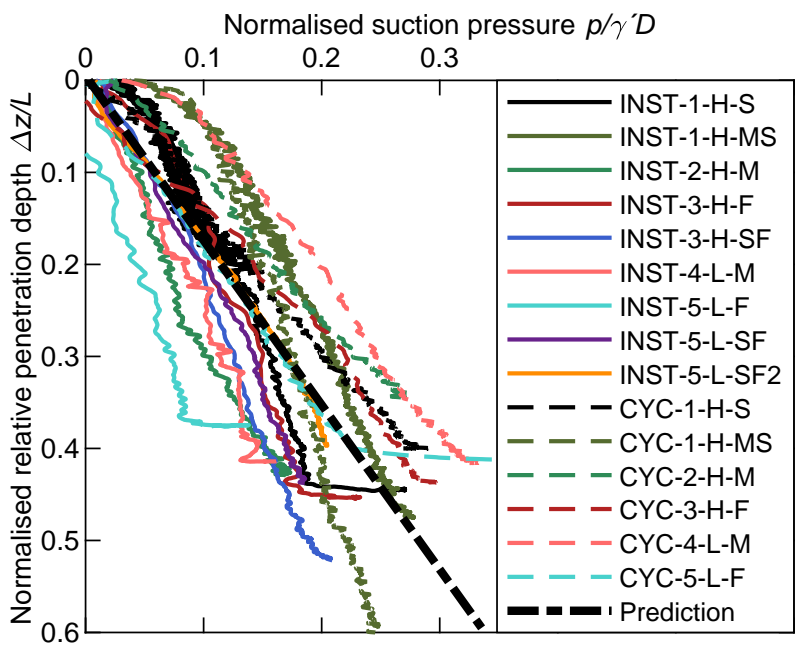

Figure 10: History of normalised suction pressure.

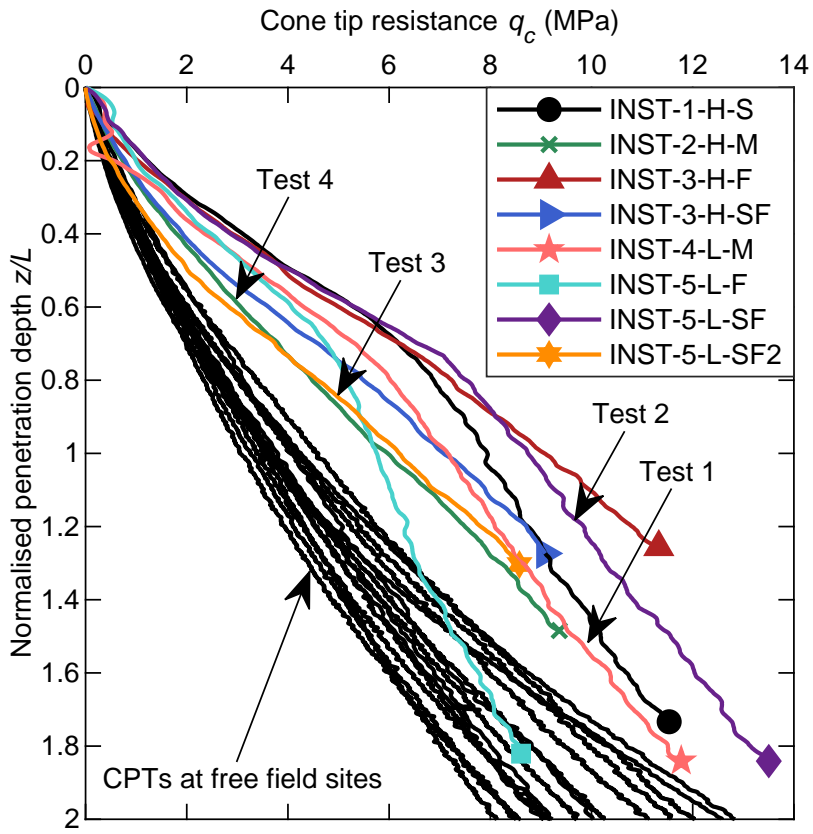

Figure 11: CPTs before and after caisson installation. 


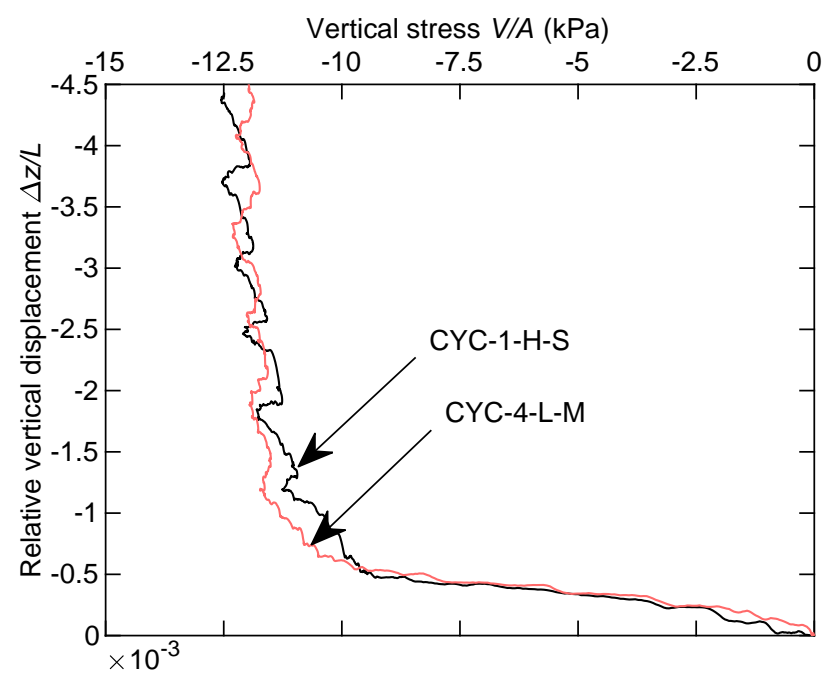

Figure 12: Drained pull-out resistance.

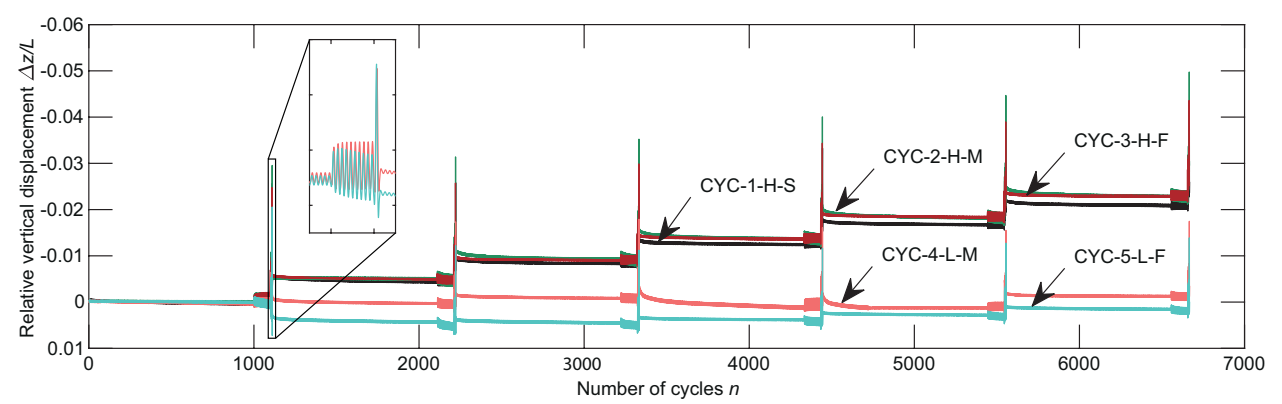

Figure 13: History of vertical displacements during cyclic loading. 


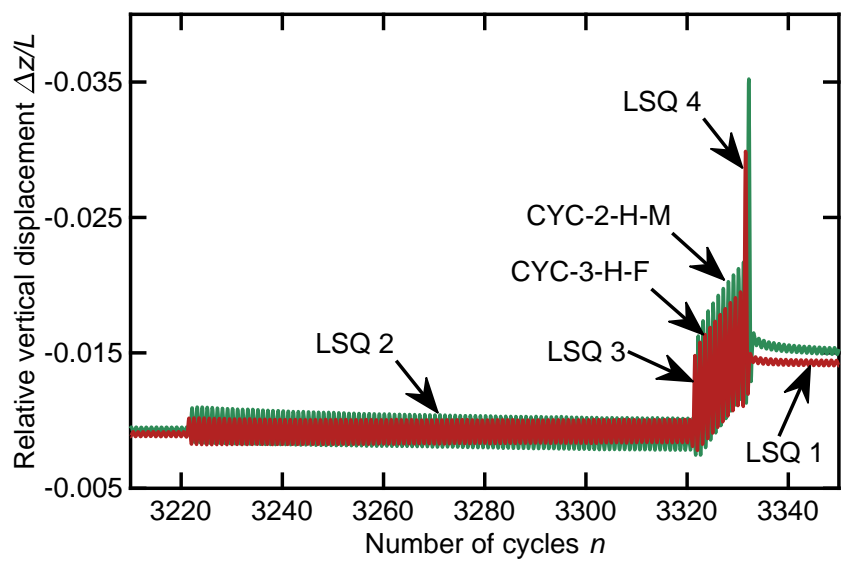

Figure 14: History of vertical displacements during cyclic loading during sequences two, three and four of the third loading package. 


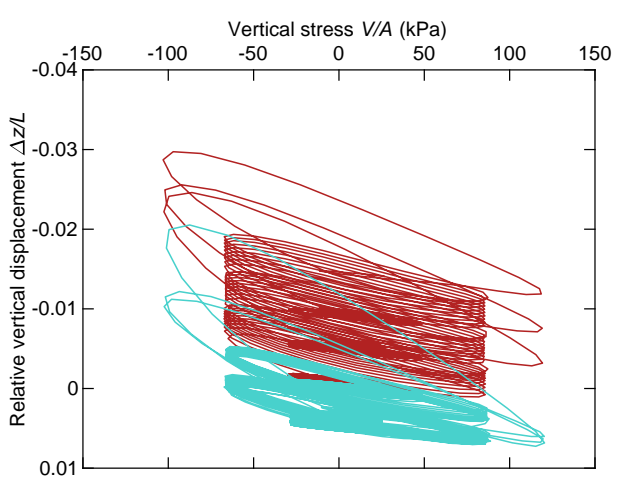

(a)

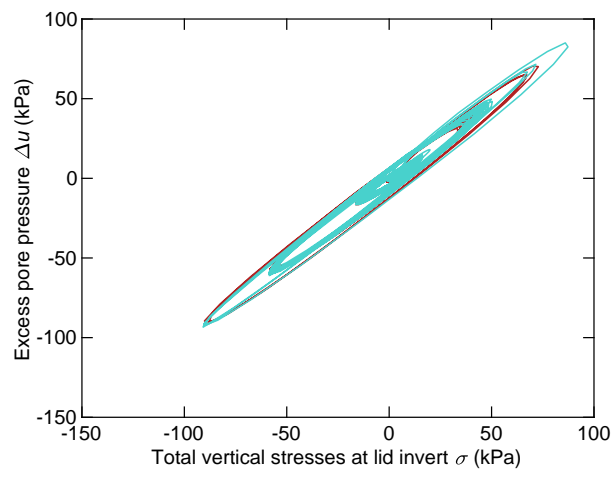

(c)

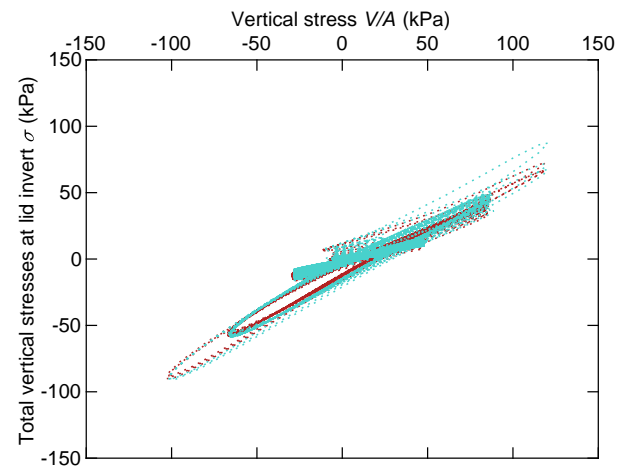

(b)

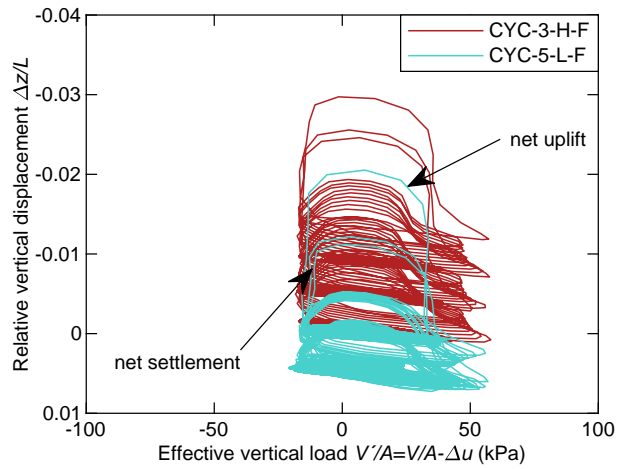

(d)

Figure 15: Effect of drainage on load transfer mechanism in tests with cyclic loading: (a) applied stress; (b) total stress at lid invert; (c) drainage at lid invert; (d) effective load at lid invert. 


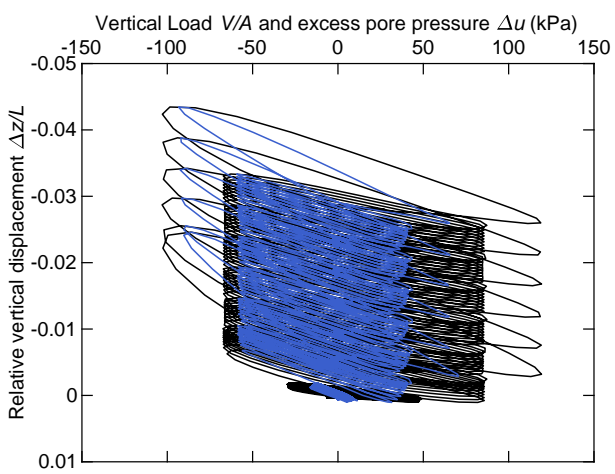

(a)

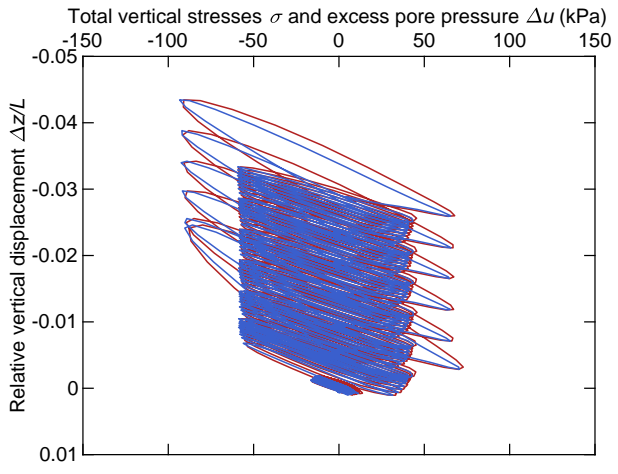

(c)

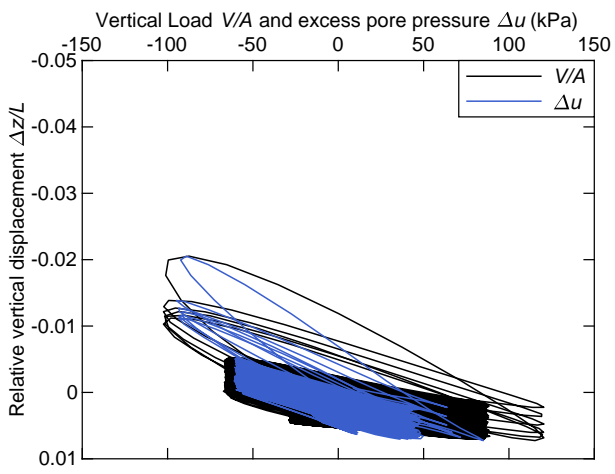

(b)

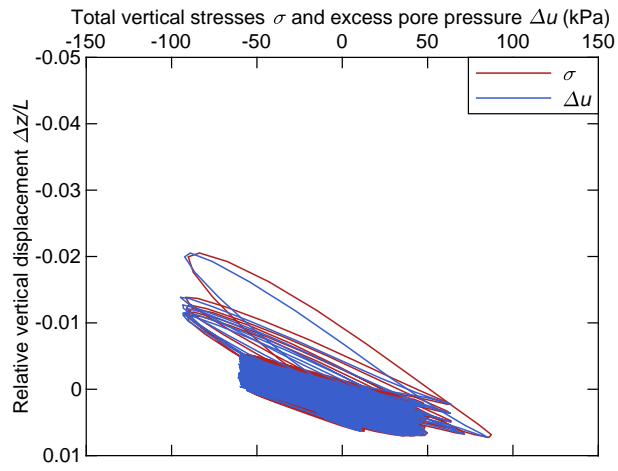

(d)

Figure 16: Caisson response over six cyclic loading sequences, applied stress and excess pore pressure at the lid invert: (a) Test CYC-3-H-F; (b) Test CYC-5-L-F; total stress and excess pore pressure at the lid invert: (c) Test CYC-3-H-F; (d) Test CYC-5-L-F.

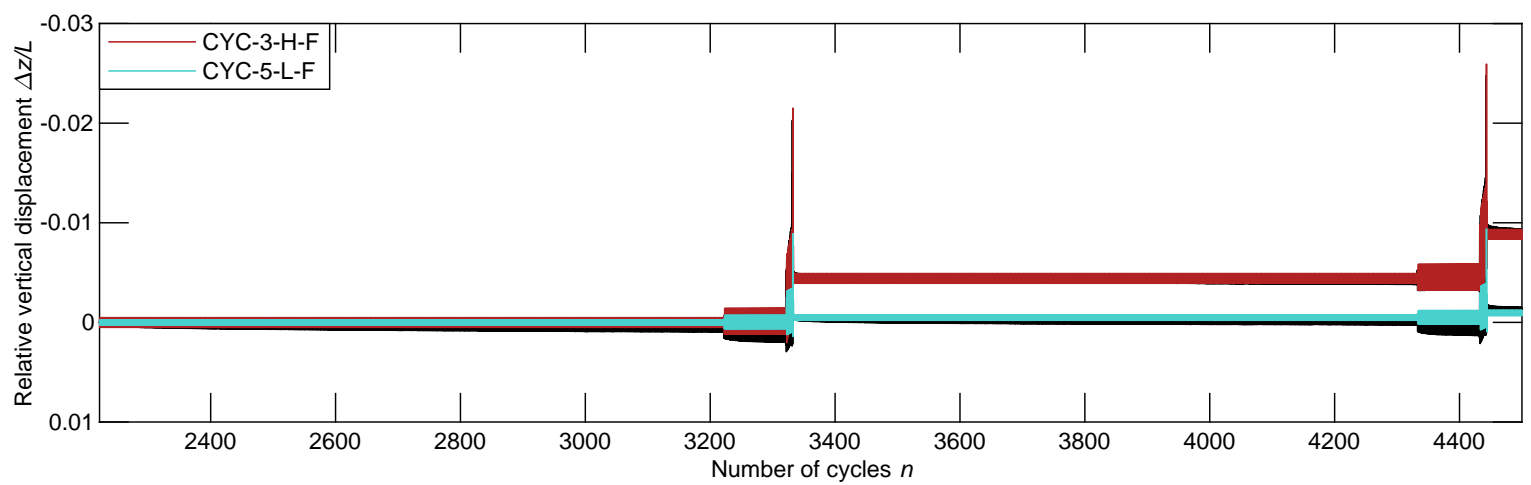

Figure 17: Predicted history of vertical displacements during cyclic loading. 